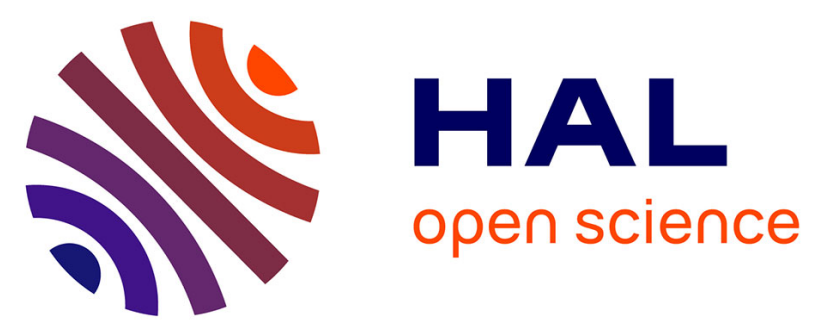

\title{
Magnetic resonance sounding measurements as posterior information to condition hydrological model parameters: Application to a hard-rock headwater catchment
}

N. Lesparre, Jean-François Girard, Benjamin Jeannot, Sylvain Weill, Marc Dumont, Marie Boucher, Daniel Viville, Marie-Claire Pierret, Anatoly Legchenko, Frédérick Delay

\section{To cite this version:}

N. Lesparre, Jean-François Girard, Benjamin Jeannot, Sylvain Weill, Marc Dumont, et al.. Magnetic resonance sounding measurements as posterior information to condition hydrological model parameters: Application to a hard-rock headwater catchment. Journal of Hydrology, 2020, 587, 10.1016/j.jhydrol.2020.124941 . hal-02558482

\section{HAL Id: hal-02558482 \\ https://hal.science/hal-02558482}

Submitted on 29 Apr 2020

HAL is a multi-disciplinary open access archive for the deposit and dissemination of scientific research documents, whether they are published or not. The documents may come from teaching and research institutions in France or abroad, or from public or private research centers.
L'archive ouverte pluridisciplinaire HAL, est destinée au dépôt et à la diffusion de documents scientifiques de niveau recherche, publiés ou non, émanant des établissements d'enseignement et de recherche français ou étrangers, des laboratoires publics ou privés. 


\title{
Magnetic resonance sounding measurements as posterior information to condition hydrological model parameters: Application to a hard-rock headwater catchment
}

\author{
Nolwenn Lesparre ${ }^{\mathrm{a},{ }^{*}}$, Jean-François Girard ${ }^{\mathrm{b}}$, Benjamin Jeannot ${ }^{\mathrm{a}}$, Sylvain Weilla, Marc \\ Dumont $^{c}$, Marie Boucher ${ }^{d}$, Daniel Vivillea, Marie-Claire Pierret ${ }^{a}$, Anatoly Legchenkod, \\ Frederick Delay ${ }^{\mathrm{a}}$
}

a Université de Strasbourg, CNRS, EOST, ENGEES UMR 7517, F-67000 Strasbourg, France

b Université de Strasbourg, CNRS, EOST, ENGEES UMR 7516, F-67000 Strasbourg, France

c Sorbonne Université, CNRS, EPHE, UMR 7619 METIS, F-75005 Paris, France.

d Univ. Grenoble Alpes, IRD, CNRS, IGE, F-38000 Grenoble, France.

* corresponding author: LHyGeS, Université de Strasbourg - 1 Rue Blessig - 67000 Strasbourg

- France- lesparre@unistra.fr

\section{Highlights}

- Magnetic resonance soundings are used to condition hydrological model parameters.

- The output of hydrological model simulations provides the subsurface water content.

- The estimated water content is then used to simulate the MRS signal.

- The comparison with observations allows selecting sets of model parameters.

- The approach is applied on a hard-rock headwater catchment.

\begin{abstract}
In headwater catchment, the calibration of hydrological models is complex due to the scarcity of data in mountainous areas. Here, an innovative methodology is developed to condition hydrological model parameters by using magnetic resonance sounding (MRS) measurements in combination with stream flow rate data. MRS has the specificity in the various geophysical imaging techniques of being mainly sensitive to the vertical distribution of water content among the subsurface. In a way very similar to hydraulic head observations, these local distributions of water content may serve as information in a hydrological model to pattern subsurface flow by seeking model parameters. Simulations are run with different sets of parameters of a hydrological model. Each simulation provides as an output a 4-D map (3-D spatial plus time) of the vertical water content distributions over the whole catchment and their fluctuations over time. This output is then used to simulate the MRS signal that would be produced by the estimated water content. The simulated MRS signal is compared to measured MRS data to determine which hydrological simulations (which model parameters) are close to observations. The approach is applied on a hard-rock headwater catchment housing a very shallow and thin aquifer where an MRS survey covers the whole studied site. Hydraulic parameters of an integrated hydrological model of the catchment are spatially distributed by zones with uniform values, the prior delineation of the zones being guided by pedological studies. As MRS measurements supply local but spatially distributed information, the method conditions the various zones on their parameter values in a much better way than the classical (in headwater catchments) measure of the stream flow rate at the outlet of the system. Finally, hydrological simulation and time-dependent MRS forward calculations can help identifying possible locations for MRS stations to monitor the transient behavior of the hydrological state of the catchment.
\end{abstract}

Keywords: Hydrological model parameters; Geophysics; Magnetic resonance sounding; Headwater catchment; Hard-rock aquifer 


\section{Introduction}

Headwater catchments are widely used for water supply services and, therefore, represent essential reservoirs for water resources management (Winter, 2007; Blumstock et al., 2016). The evolution of groundwater storage in such systems in response to climatic forcing is also of great importance as it controls the amount of water and elements released to the downstream part of rivers, supports ecosystem services, and strongly impacts the amplitude of streamflow during low-flow and high-flow periods (Rinderer et al., 2014; Blumstock et al., 2016). Water circulation in such environments is complex as it is shaped by the strong heterogeneity of the subsurface medium and lacks homogenization usually brought by large-scale systems (Beven et al., 1988; Ameli et al., 2016; Chorover et al., 2017; Kim et al., 2017; Riebe et al., 2017; Dwivedi et al., 2019). In the context of hardrock geology, the spatial variability of the hydraulic properties from the superficial soils to the deeper bedrock substantially impacts the hydrological catchment response to rainfall (Banks et al., 2009; Gannon et al., 2014; Diek et al., 2014; McMillan and Srinivasan, 2015; Welch et al., 2014; Singh et al., 2018). Moreover, the interfaces between the different subsurface compartments (i.e., soil, saprolite, fractured bedrock, and fresh bedrock) might be of complex geometry influencing groundwater flow paths and the associated transit and residence times of water (Koch et al., 2009; Kosugi et al., 2011; Welch et al., 2014; Gabrielli et al., 2012; Rempe and Dietrich, 2014; Comte et al., 2019).

Characterizing the heterogeneity of the hydraulic parameters in the subsurface and the geometry of the subsurface layers is still a challenge in hydrology (Salve et al., 2012; Koïta et al., 2017; Comte et al., 2019). A proper characterization is nonetheless critical to reduce equifinality issues when using models that describe the water cycle at the catchment scale. This is especially true for headwater catchments because these systems likely conceal a strong variability in terms of soil properties, topographic interfaces, and lithology. Indeed, geochemical data analyses using tracer data highlighted the heterogeneity of the reservoirs supplying mountainous streams (Koch et al., 2017; Kim et al., 2017; Wymore et al., 2017). Modeling the streamflow at the outlet of a catchment was also shown to render non-unique solutions due to the aggregated nature of the data convoluting the effects of various local behaviors and heterogeneities over the whole system (Ebel and Loague, 2006). Calibrating a model by relying upon streamflow data only is known to be inefficient or at least highly uncertain. The classical hydrogeological strategy that consists of fitting piezometric data from open boreholes remains arduous to set up in mountainous contexts where the field is hardly accessible to drilling works. In addition, piezometric data provide limited information regarding headwater catchments, which means that only the local position of the water table is given when very shallow and thin aquifers would be better documented by measurements of the water content evolution with depth. Alternative strategies are needed to properly constrain hydrological models able to produce reliable simulations of the transient response of headwater catchments and thus improve our current understanding of streamflow generation processes in such environments (Weill et al., 2019).

The use of geophysical methods, such as electrical resistivity, seismic tomography, or ground penetrating radar, provides insights into the structure of subsurface systems and allows for defining zones of different properties, including the thickness of hydraulically-active layers (Koch et al., 2009; Befus et al., 2011; Cassidy et al., 2014; Holbrook et al., 2014; Parsekian et al., 2015; Soulsby et al., 2016; Olyphant et al., 2016; Orlando et al., 2016; Koïta et al., 2017; Flinchum et al., 2018a). Time-lapse experiments also inform on the processes driving the water circulation along hillslopes or in a catchment (Cassiani et al., 2009; Angermann et al., 2017; Jackisch et al., 2017; Scaini et al., 2018; Hübner et al., 2017; Kotikian et al., 2019). In the first step, the images of geophysical properties provide qualitative information on the subsurface structures or on the active dynamic processes. In the second step, petrophysical relationships allow a deeper interpretation of geophysical information by rendering a quantitative estimate of hydraulic parameters, such as porosity (Tureson, 2006; Mota and Monteiro Santos, 2010; Holbrook et al., 2014; Rehman et al., 2016; Flinchum et al., 2018b; Comte et al., 2019), water content (Daily et al., 1992; Turesson, A., 2006; Mota and Monteiro Santos, 2010), or, sometimes, hydraulic conductivity values (Chen et al., 2001; Slater, 2007; Léger et al., 2014; Gottschalk 
et al., 2017). Some developments of coupled inversions between geophysical data and hydrological models help to cope with the uncertainties stemming from deterministic inversions converting geophysical signals into images of the subsurface properties. For example, coupled inversions allow for by-passing the effects of a degrading resolution of the geophysical image with depth or a smoothing effect related to the regularization applied to address the non-unicity of the solutions (Hinnel et al., 2010; Binley et al., 2015). However, coupled inversions still require the use of empirically estimated petrophysical relationships whose application remains risky at a catchment scale. In fact, the petrophysical relationships may vary spatially as they rest on links between hydraulic and geophysical properties that are specific to a given site, the scale investigated, and the geological settings of the studied domain (Christensen et al., 2016).

Magnetic resonance soundings (MRS) provide data that are directly sensitive to the subsurface water content without resorting to any variable petrophysical law (Legchenko et al., 2004; Costabel and Günther, 2014). The acquisition of such data is non-invasive and supplies information concerning both the saturated and unsaturated zones of the subsurface (Mazzilli et al., 2016). MRS measurements offer a direct estimate of the aquifer's free water content from which the effective porosity is deduced when the thickness of water-bearing layers is provided by other data. They also allow for evaluating indirectly the hydraulic conductivity via calibrations from pumping tests (Legchenko et al., 2004) or sampling analysis (Mohnke and Yaramanci, 2008). An MRS survey performed on a network of stations strategically designed offers the opportunity to obtain direct insights on the spatial distribution of hydraulic variables at the catchment scale even if the system shows a strong spatial heterogeneity in terms of lithology or mineralogy. Furthermore, MRS measurements integrate the subsurface water content over "plugs," depending on the geometry of the acquisition device, but they are usually of a few tens of meters in lateral and vertical extension (Legchenko et al., 2004). Such sizes are comparable to the classical mesh resolution (a few tens of $\mathrm{m}$ ) of hydrological models for small catchments (1 $10 \mathrm{~km}^{2}$ ), thus more easily rendering the integration of MRS data into a modeling task.

To date, most studies based on MRS data are devoted to systems where the thickness of the saprolite and the weathered bedrock are of a few tens of meters (Legchenko et al., 2006; Descloitres et al., 2008; Francés et al., 2014; Vouillamoz et al., 2014, 2015; Koïta et al., 2018). Sites affected by Ice Age footprints show much thinner saprolite and weathered bedrock layers with thicknesses of a few meters, due to intense erosion processes (Fichter et al., 1998b; Sailhac et al., 2009; Comte et al., 2019). Despite the difficulty of probing the very shallow subsurface, the combination of MRS data with other geophysical methods is very fruitful for revealing information on the saprolite and weathered rock hydraulic properties (Wyns et al., 2004; Baltassat et al., 2005; Sailhac et al., 2009; Comte et al., 2019). In most of the previous studies reported by the literature, MRS data are classically inverted to estimate the medium porosity and its hydraulic conductivity. This information is later used as a prior guess in hydrological models at the hillslope or the catchment scale (Lubczynski and Gurwin 2005; Boucher et al., 2012; Comte et al., 2019). Nevertheless, equifinality issues arise in the reconstruction process of the vertical distribution of water content and layer thicknesses that should condition the hydrological model (Costabel and Günther, 2014). This downside is emphasized when hydraulic conductivity estimates rest on empirical relationships that might spatially vary over the catchment. Nonetheless, the coupling of MRS data with hydrogeological models is a powerful strategy to tackle non-unicity issues as reported by a few studies to model pumping tests (Herckenrath et al., 2012; Vilhelmsen et al., 2014), the capillary fringe (Costabel and Günther, 2014), the evaporation in the first centimeters of soils (Merz et al., 2018), or the water movement in variably saturated media (Legchenko et al., 2020).

In this study, an alternative methodology is proposed. The idea is to turn upside down the classical formalism described previously and use MRS measurements as posterior information to constrain the subsurface parameters of the hydrological model. Instead of determining a prior spatial distribution of the hydraulic properties and the aquifer geometry from MRS, the data are used as a calibration observation in the hydrological model as would be classical streamflow measurements or piezometric data. The water content simulated by the hydrological model for a given set of model parameters is 
Lesparre et al., 2020, J. of Hydrol.

used to compute the resulting MRS signals that are then compared to the measured data. The quality of fitting between MRS simulations and data then serves as the trigger to change (in a Monte-Carlo approach) the set of hydrological parameters. As a proof of concept, this methodology is applied to the Strengbach catchment - a mountainous catchment belonging to the French network of criticalzone observatories (Pierret et al., 2018). The model used in the study is an integrated hydrological model (i.e., a model that couples surface and subsurface flow processes) called NIHM (Normally Integrated Hydrological Model; Pan et al., 2015; Weill et al., 2017; Jeannot et al., 2018). Both streamflow and MRS data are employed to define a set of parameters allowing for describing both the hydrological response at the outlet and the local evolution of subsurface water content identified by MRS measurements. The quality of the optimal set of parameters is then assessed using a long-term streamflow chronicle.

The paper is organized as follows: Section 2 is dedicated to the presentation of the MRS method and the computation of MRS signals from water content estimates. Section 3 details the hydrological modeling strategy with emphasis on the assumptions that ground the NIHM model, and the way the water content is estimated. In Section 4, the field application of the proposed methodology is described. The results are presented and discussed in the last section of the paper.

\section{MRS method}

\subsection{Principle and implementation}

MRS is a geophysical method directly sensitive to the quantity of water molecules present in the subsurface. MRS is conducted by recording the response of energized nuclei of hydrogen atoms only contained in water molecules (in the absence of hydrocarbon). To do so, an alternating current is injected at fixed pulse moments and Larmor frequency in wire loops of decametric size placed on the ground surface. The pulse moment corresponds to the product of the injected current intensity by the pulse duration, and the Larmor frequency represents the precessing frequency of the hydrogen nuclear spins and depends on the local geomagnetic field (Legchenko et al., 2002). Then, the excited spins of the hydrogens nuclei are forced to tilt away from their equilibrium state. After the energizing pulse is switched off, spins relax back to their initial state; the nuclei of hydrogen atoms reemit the accumulated energy, producing an electromagnetic signal (Legchenko et al., 2004). The same wire loops can be used to measure the temporal variation of the voltage induced by the electromagnetic response. The recorded signal oscillates at Larmor frequency and decays at a characteristic relaxation time $T_{2}^{*}(z)$ which depends on the pore space characteristics. The MRS noise amplitude is generally evaluated by recording environmental noise over a duration similar to the MRS recording time, with the same loop, but before the MRS exciting pulse is emitted. The overall measuring protocol described just above is called free induction decay (FID). In the specific cases where the subsurface medium has significant magnetic properties, the FID signal can be perturbed, but protocols called spin echo can be used by injecting a second electromagnetic pulse (Shushakov and Fomenko, 2004; Legchenko et al., 2010; Grunewald et al., 2014).

The MRS measured signal is all the more sensitive to the deeper part of the subsurface that the loop is wider or the injected pulse is stronger. The classical strategy is to fix the dimension of the loop such as it corresponds to the maximum sounded depth contemplated. Measurements are then repeated with different pulses of higher energy to progressively increase the depth sounded in the subsurface (Legchenko, 2002). Classically, an inversion is then performed to reconstruct the vertical distribution of the water content $\theta(z)$ and the relaxation time $T_{2}^{*}(z)$. A higher subsurface water content induces a stronger amplitude of the measured signal, with the consequence that media characterized by a very small water content are susceptible to show low signal to noise ratios. Most MRS equipment used for aquifer characterization is only sensitive to free water (which can move under gravity-driven forces) but is not able to detect bound water as, for example, inter-layer water molecules in clay minerals (Boucher et al., 2011). 
Lesparre et al., 2020, J. of Hydrol.

Large values of $T_{2}^{*}(z)$ indicate a coarse material, while smaller values correspond to a fine-grained material. $T_{2}^{*}$ is related to the transversal relaxation time of the MRS signal $T_{2}$ by $1 / T_{2}^{*} \approx 1 / T_{2}+\mu \Delta B_{0} / 2$, where $\mu$ is the gyromagnetic ratio for protons and $\Delta B_{0}$ the magnetic gradient at the pore scale. $T_{2}$ reflects directly the pore space characteristics because $1 / T_{2} \approx \rho_{2} . S_{\text {pore }} / V_{\text {pore }}$ (Kleinberg et al., 1994; Kenyon, 1997), with $\rho_{2}$ being the surface relaxivity (i.e., the property of the surface of the rocks to enhance relaxation), and $S_{\text {pore }}$ and $V_{\text {pore }}$ corresponding to the inner surface and the volume of the pores, respectively. Empirical but also more sophisticated models are able to link the MRS response of rocks to their permeability and saturation (Falzone and Keating, 2016; Dlugosch et al., 2013). However, reliable values of $T_{2}^{*}$ are required for estimating the rock permeability or the pores characteristics (Vouillamoz, 2012).

\subsection{MRS model}

Assuming a vertical distribution of the water content $\theta(z)$ and a mono-exponential relaxation characteristic time $T_{2}^{*}(z)$, the MRS envelop $V(q, t)$ decaying with time $t$ for a pulse moment $q$, can be written as (Legchenko and Valla, 2002):

$$
V(q, t)=\int_{z} \kappa(q, z) \cdot \theta(z) \cdot \exp \left(-t / T_{2}^{*}(z)\right) \mathrm{dz} .
$$

The 1-D time-invariant kernel function $\kappa(q, z)$ of the MRS vertical sensitivity is conditioned by:

- The geomagnetic field amplitude and the Larmor frequency.

- The electrical resistivity distribution.

- The geometry of the acquisition system, i.e., the shape and the size of the injecting-collecting wire loop.

- The amplitude of the injected pulse current $q$.

- The distribution of the subsurface layers in which $\theta(z)$ and $T_{2}^{*}(z)$ are provided.

The use of the MRS signal envelop integrated along the recording time is particularly relevant when the measured signal to noise ratio is weak because of a small water content or a strong environmental noise. The signal to noise ratio of the integrated MRS signal is increased by averaging real and imaginary parts of the signal in the same envelope while avoiding vast loss of information. From Eq. 1, the integrated signal $\mathcal{A}_{\mathrm{est}}(q)$ of the estimated MRS signal over time writes:

$$
\mathcal{A}_{\mathrm{est}}(q)=\int_{z} K(q, z) \cdot \theta(z) \cdot T_{2}^{*}(z) \cdot\left[\exp \left(-t_{s} / T_{2}^{*}(z)\right)-\exp \left(-t_{e} / T_{2}^{*}(z)\right)\right] d z
$$

with $t_{s}$ the acquisition start time and $t_{e}$ the end of the acquisition time. The fit quality between the estimated and measured MRS signals (i.e., the objective function) can then be expressed by comparing $\mathcal{A}_{\text {est }}(q)$ with the measured signal area $\mathcal{A}_{\text {mes }}(q)$ which error is estimated by the measured noise area $\mathcal{A}_{\text {noise }}(q) . \mathcal{A}_{\text {mes }}(q)$ and $\mathcal{A}_{\text {noise }}(q)$ that are also integrated values over time, are both computed using the trapezium rule on the raw measurements.

\subsection{MRS model parameterization}

In this study we propose to use MRS data as a posterior information to condition a hydrological model simulating water flows at the catchment scale. The water content vertical distribution $\theta(z)$ at the locations of MRS station is supplied by one of the hydrological model outputs, as described in the 
following Section. The fact remains that the vertical distribution of the variable $T_{2}^{*}(z)$ should be prescribed to solve Eq. 2. Those values are determined via a simple least-square technique. We limited at two the number of sought $T_{2}^{*}(z)$ values to reduce equifinality issues associated with an excessive number of parameters. To do so, the raw MRS measurements are post-processed by seeking, for each pulse $q$, the best model $W(q, t)$ for the envelope of the signal measured over time as:

$$
W(q, t)=A_{\text {app }}(q) \exp \left(-t / T_{\text {2app }}^{*}(q)\right)
$$

where $A_{\text {app }}$ and $T_{2 \text { app }}^{*}$, respectively, correspond to the apparent amplitude and the apparent relaxation terms of the raw signal measured in the field. Examples of the estimation of $A_{\text {app }}$ and $T_{2 \text { app }}^{*}$ to fit the signals acquired for the different pulses applied at the MRS stations are shown in Lesparre et al. (submitted). The aim of this fit is simply to get an insight on the $T_{2 \text { Med }}^{*}=\operatorname{median}\left(T_{\text {2app }}^{*}(q)\right)$ values for each station, $T_{2 \text { Med }}^{*}$ being used later as a prior estimate of the $T_{2}^{*}(z)$ that shapes the simulated MRS signal (Eq. 2). Assuming that $T_{2}^{*}(z)$ is relatively homogeneous over depth, its prior value is set to $T_{2 \mathrm{Med}}^{*}$ and its variation range is bounded by $0.2 \cdot T_{2 \mathrm{Med}}^{*}$ and $5 \cdot T_{2 \mathrm{Med}}^{*}$. The $T_{2 \mathrm{Med}}^{*}$ estimated for the different stations are summarized in Table 1 in Lesparre et al. (submitted). The $T_{2 \mathrm{Med}}^{*}$ estimate is an apparent value which does not reflect the $T_{2}^{*}(z)$ of the subsurface; therefore, no interpretation is made on the $T_{2 \text { Med }}^{*}$ values.

\section{Hydrological model}

\subsection{The Normally Integrated Hydrological Model (NIHM)}

NIHM is physically-based and spatially distributed hydrological model to describe and couple the flow processes occurring in the surface and subsurface compartments of a catchment from local to regional scales (Pan et al., 2015; Weill et al., 2017; Jeannot et al., 2018). The model describes flows in the subsurface, in a 1-D stream network, and over the 2-D land surface. Only 1-D routing via the stream network and subsurface flow are presented below since diffuse 2-D surface run-off or exfiltration from the subsurface have never been evidenced at the Strengbach catchment. The absence of surface run-off is associated with the presence of sandy soils that favor rapid infiltration (Pierret et al., 2018) even over steep slopes that usually trigger run-off. NIHM belongs to the so-called simplified "low-dimensional" models, mainly because the full 3-D Richards equation for flow in the subsurface is integrated along a direction perpendicular to the substratum with the idea to treat the subsurface compartment as a single two-dimensional layer. To this end, flow within the 3-D subsurface domain is modeled through a 2-D equation, while hydraulic parameters are defined in several layers. The variation of the hydraulic parameters over depth is then taken into account when performing the flow integration perpendicularly to the substratum, via mean (integral) parameters over the saturated and unsaturated thicknesses of the subsurface. This technique drastically reduces the meshing effort, the required memory space, and the computational cost while preserving the physics, especially for systems with a contrasted topography as in the Strengbach catchment. The description of flow in the 1-D stream network is based on a 1-D formulation of the diffusive wave approximation of the St-Venant equations that neglects inertial effects over very short periods (less than $100 \mathrm{~s}$ ) eventually occurring in surface-routed flow. The set of equations that are solved can be written as:

$$
\begin{gathered}
\frac{\partial \bar{\theta}_{I}(h)}{\partial t}+\bar{S}(h) \frac{\partial h}{\partial t}+\nabla_{x, y} \cdot\left(-\overline{\mathbf{T}}(\theta) \nabla_{x, y} h\right)=Q_{w} \\
l_{r} \frac{\partial h_{r}}{\partial t}-\nabla_{x} \cdot\left(k_{p} \nabla_{x}\left(h_{r}+z_{r}\right)\right)=l_{r} \gamma_{1 D}
\end{gathered}
$$


with $\bar{\theta}_{I}(h)=\int_{z_{w}}^{z_{s}} \theta(z) d z ; \bar{S}(h)=\overline{S S}_{\text {sat }} h ; \overline{\mathbf{T}}(h, \theta)=\overline{\mathbf{K}}_{\text {sat }} h+\int_{z_{w}}^{z_{s}} \mathbf{K}(\theta(z)) d z$

$\overline{\mathbf{K}}_{\text {sat }}\left[\mathrm{LT}^{-1}\right]$ is the saturated hydraulic conductivity tensor, and $\overline{S S}_{\text {sat }}\left[\mathrm{L}^{-1}\right]$ is the specific storage capacity in the saturated zone; both are averaged along the integration direction $z[\mathrm{~L}] . \theta[-]$ is the water content; $\mathbf{K}\left[\mathrm{LT}^{-1}\right]$ is the tensor of hydraulic conductivity; $h[\mathrm{~L}]$ is the hydraulic head (or the capillary head) in the subsurface; $Q_{w}\left[\mathrm{LT}^{-1}\right]$ is a source/sink term that accounts for both injection-withdraw in the system and interactions with the 1-D river network; and $z_{w}, z_{s}[\mathrm{~L}]$ are the local coordinates along the direction $z$ (normal to substratum) of the water table and land surface, respectively. $h_{r}[\mathrm{~L}]$ is the water depth in the river network; $z_{r}[\mathrm{~L}]$ is the elevation of the river bed; $l_{r}[\mathrm{~L}]$ is the wetted width in the river; $k_{p}\left[\mathrm{~L}^{3} \mathrm{~T}^{-1}\right]$ is a conduction term that depends on geometrical parameters of the network, the Manning roughness coefficient, and the surface water depth $h_{r}$; and $\gamma_{1 D}\left[\mathrm{LT}^{-1}\right]$ is a source/sink term accounting for the stream network interactions with the subsurface. For the application to the Strengbach catchment, we consider that the hydraulic conductivity tensors $\mathbf{K}$ and $\overline{\mathbf{K}}_{\text {sat }}$ are isotropic, so they are reduced to the scalar values $K$ and $\bar{K}_{\text {sat }}$, respectively.

Interactions (coupling) between the surface and subsurface compartments rely upon a firstorder approximation setting the exchanged water fluxes between the compartments as proportional to the head difference between the compartments. The equations are solved together using a fully implicit approach and advanced numerical schemes. A full description of the model and of the numerical techniques is available in Jeannot et al. (2018). Various comparisons and bench tests (Weill et al., 2017; Jeannot et al., 2018) showed that simplifications brought by NIHM in the flow processes did not jeopardize accurate applications to complex hydrosystems (Jeannot et al., 2019).

\subsection{Water content estimate}

NIHM calculates the water pressure (expressed in height of fluid above a given elevation) $\psi[\mathrm{L}]$ in each element of the catchment model and at each observation time. From $\psi$, the Van Genuchten (1980) equations can provide the vertical distribution of the water content $\theta(z)$, which is then used for the MRS signal estimates compared with observations. For each hydrologic simulation, NIHM can supply outputs in the form of 4-D maps of water content (3-D spatial plus time). As NIHM is characterized by a two-dimensional integrated subsurface compartment, the three-dimensional reconstruction of the water content in the subsurface needs a few explanations. For the sake of simplicity but without loss of generality, it is dealt hereafter with a horizontal aquifer where the vertical direction $z$ is that of the normal-to-substratum direction of integration employed by NIHM.

In NIHM, the hypothesis is that subsurface flow is mainly parallel to the substratum, which implies that for Darcian flow, there will be an instantaneous hydrostatic equilibrium along the $z$ direction with the hydraulic head gradient component $\partial h / \partial z=0$. For an incompressible fluid at hydrostatic equilibrium and with very small fluid velocity (i.e., neglecting kinetic energy of the fluid), the Bernoulli's theorem states that at any elevation $z_{p}$ above a prescribed reference between the substratum $z_{b}$ and the surface $z_{s}$ along the vertical direction $z, h=\psi_{p}+z_{p}$, where $\psi_{p}$ corresponds to the water pressure at the elevation $z_{p}$. The null gradient $\partial h / \partial z=0$ assumes that $h$ is uniform over $z$ at the value of the saturated water table elevation $z_{w}$. Therefore, $\psi_{p}=z_{w}-z_{p}$, which renders positive values in the saturated zone $z_{b}<z_{p} \leq z_{w}$ and negative values in the unsaturated zone $z_{w}<z_{p} \leq z_{s}$. It is worth noting that NIHM can calculate hydraulic heads $h=z_{w}$ beneath the substratum $z_{b}$. In that case, the aquifer is completely unsaturated along $z$, but the calculation of $\psi$ 
Lesparre et al., 2020, J. of Hydrol.

still applies. In the same vein, for hydraulic heads $h=z_{w}$ above the surface $z_{s}$, the system is always saturated locally along the direction $z$, exfiltration from the subsurface through the surface occurs, and $\psi$ is always positive along $z$. Knowing the values $\psi(z)$ at any elevation $z$, the Van Genuchten (1980) equations provide the vertical distribution of the water content in the form:

$\theta(z)= \begin{cases}\left(\theta_{s}-\theta_{r}\right)\left[1+(\alpha|\psi(z)|)^{n}\right]^{-m}+\theta_{r}, & \text { if } \psi<0 \\ \theta_{s}, & \text { if } \psi \geq 0\end{cases}$

where $\theta$ is the effective saturation [-], $\theta_{s}$ is the saturated water content [-], and $\theta_{r}$ is the residual water content [-]. $\alpha$ is a parameter related to the mean pore size $\left[\mathrm{L}^{-1}\right], n$ is a parameter reflecting the uniformity of the pore size distribution [-], and $m$ is a parameter defined by $m=1-1 / n$ [-] (Mualem, 1976). The notation in Eq. 6 overlooks the eventual variability over the direction $z$ of all parameters, e.g., $\theta_{s}(z)$.

\section{Overall methodology}

\subsection{Workflow}

A flowchart summarizes the developed methodology (Fig. 1), which proceeds according to the following schedule:

1. Partition of the catchment in zones inheriting for partitions delineated by pedological, geomorphological and geological studies (Fig. 2).

2. Set up of the NIHM parameters (aquifer thickness, porosity and hydraulic conductivity) defined as uniform values in each zone (Fig. 3).

3. Forward simulation via NIHM of hydraulic heads in the subsurface and flow rates in the streams.

4. Calculation of the subsurface vertical distributions of water contents from the estimated heads in the subsurface using the Van Genuchten model (1980).

5. Assignment of the water contents $\theta(z)$ from a NIHM simulation to the MRS forward model (Eq. 2), and search of the relaxation times $T_{2}^{*}(z)$ by a least-square fitting of the MRS simulated signals onto the MRS data.

6. Evaluation of the fit quality for both MRS simulated signals and NIHM simulated flow rates with their equivalent in terms of observed data.

The steps 2 to 6 are inserted in a loop with the re-assignment of the NIHM parameters within the defined zones of the catchment until reaching fair fits of both MRS and flow rate data. 


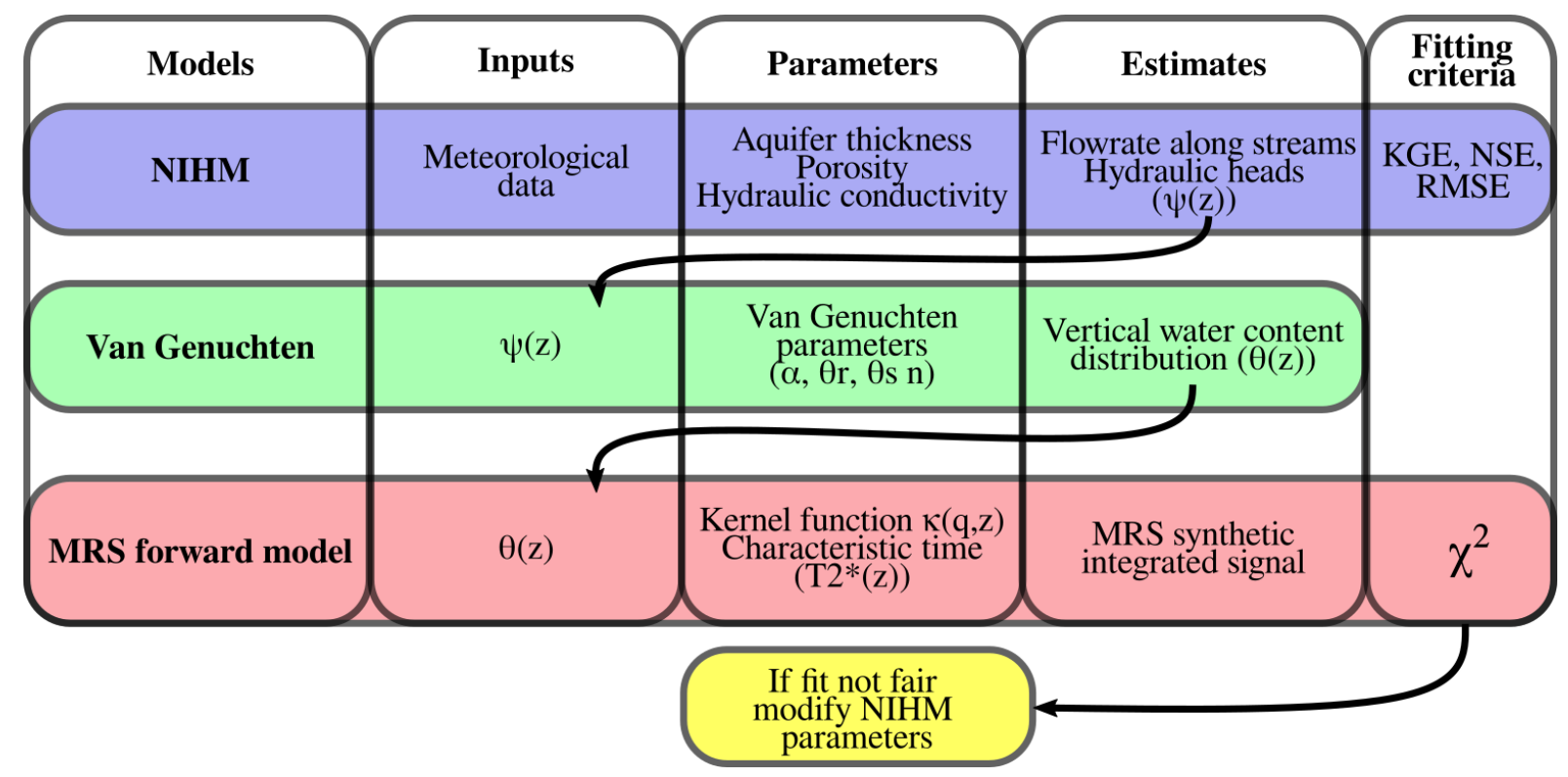

Figure 1 : Flowchart of the overall methodology developed to condition hydrological model parameters from MRS measurements.

\subsection{Fitting criteria}

For the calibration process, NIHM simulations are run over an eight-month period from October 1, 2012, to May 31, 2013. The first four months are used to "warm-up" the simulations (rendering them independent of eventually flawed initial conditions), while the remaining four months allow for the calibration of NIHM with simulated MRS data and flow rate at the outlet compared with the corresponding observations. The evaluation of the flow rate fit quality is computed using the KlingGupta efficiency (KGE), the Nash-Sutcliffe efficiency (NSE) and the root mean square error (RMSE) criteria defined as:

$$
K G E=\sqrt{(r-1)^{2}+(\eta-1)^{2}+(\beta-1)^{2}},
$$

where $r$ is the correlation coefficient between the simulated and observed discharges, $\eta$ is the ratio between the mean simulated and mean observed discharges, and $\beta$ is the ratio between the standard deviations of the simulated and observed discharges.

$$
N S E=1-\frac{\sum_{i=1}^{N}\left(Q_{s}\left(t_{i}\right)-Q_{o}\left(t_{i}\right)\right)^{2}}{\sum_{t=1}^{N}\left(Q_{o}\left(t_{i}\right)-\bar{Q}_{o}\right)^{2}}
$$

where $Q_{s}\left(t_{i}\right)$ and $Q_{o}\left(t_{i}\right)$ are, respectively, the simulated and observed discharge at time $t_{i} \cdot \bar{Q}_{o}$ is the average of the observed discharge, and $N$ the number of observation times.

$$
R M S E=\sqrt{\frac{\left.\sum_{i=1}^{N}\left(Q_{s}\left(t_{i}\right)\right)-Q_{o}\left(t_{i}\right)\right)^{2}}{N}},
$$

An optimal fit would render $K G E=1, N S E=1$, and $R M S E=0 ~ I . s^{-1}$; the fit can be considered as fair to good when KGE $>0.7, \mathrm{NSE}>0.7$, and in the present case $\mathrm{RMSE}<10 \mathrm{I} . \mathrm{s}^{-1}$. 
Lesparre et al., 2020, J. of Hydrol.

Concerning the MRS data, we use the $\chi^{2}$ as an error weighted misfit value to evaluate the gap between measurements and estimates (Günther and Müller-Petke, 2012; Costabel and Günther, 2014); the best fits render values close to one:

$$
\chi^{2}=\sqrt{\sum_{i=1}^{N} \frac{\left(\left|\mathcal{A}_{\text {est }}\right|_{i}-\left|\mathcal{A}_{\text {mes }}\right|_{i}\right)^{2}}{N\left|\mathcal{A}_{\text {noise }}\right|_{i}^{2}}},
$$

with $i$ the index of the corresponding pulse and $N$ the number of pulses acquired.

\section{Field application}

\subsection{Studied site}

The Strengbach catchment is located on the upper crests of the Vosges Mountains (Northeast France). The forest covers $90 \%$ of the catchment and is primarily populated with spruces (mainly Piceas abies L.; 80\%) and beeches (Fagus sylvatica L.; 20\%). The watershed covers approximately $0.8 \mathrm{~km}^{2}$ of surface area, in which the elevation ranges between 883 and 1146 masl. Heavily incised slopes pattern the topography with an average slope of $15^{\circ}$ but locally reaching up to $30^{\circ}$ (Fig. 2). Two main hillsides compose the catchment, displaying distinct meteorological and topographic parameters related to their respective orientation. The south-eastern hillside is mainly north-exposed with weaker slopes, and it is usually colder, more humid, and rainier than the south-exposed north-western hillside.

The bedrock of the catchment is mainly composed of Hercynian granite poor in calcium ( $315 \pm 7$ million yr). Micro-granite and gneiss also outcrop locally along the southern and northern hillsides, respectively (EI Gh'Mari,1995). Above the bedrock, soils are approximately $1 \mathrm{~m}$ thick with a coarsely grained texture, sandy, and rich in gravel (Fichter et al., 1998a). The thickness of the granitic saprolite (heavily weathered rock) is estimated to vary between 1 to $9 \mathrm{~m}$, with a southern hillside presumably having a thicker weathered layer compared with the northern side (El Gh'Mari, 1995). However, the shallow subsurface of the northern hillside exhibits a higher macroporosity compared with the southern hillside. A denser network of fissures/fractures is indeed expected as granites on the northern slope have been altered by hydrothermal circulations that occurred $180 \mathrm{My}$ ago (Fichter et al., 1998b). A delimitation of pedologic zones has been drawn from a structural study of the slope incision, complemented by the analysis of 44 soil profiles covering the whole catchment, and by field observations of geomorphological and geological features (Fig. 2). Acrisols cover the crests and the slopes of the catchment, with podzols also present along the slopes. Colluviums cover the flat zone at the spring of the main stream, while the area encompassing the stream outlet is covered by gleysoils (i.e., a wetland soil almost permanently water-saturated). Surrounding that gleysoil zone, the soil is of ranker type. Narrow corridors of brown earths occur where the slopes are steep and the water saturation potential is high (Fig. 2). 
Gleysols downslope alluvium-colluvium Gleysols valley alluvium-colluvium Colluvium in valley bottom with blocks Brown earth of slopes $+/$ - covered by colluvium Rankers of steep slopes Acrisols of weathered slopes Acrisols of convex slope Acrisols of summital zone on granite Acrisols of summital zone on gneiss Acrisol on sandy granite

二 Topography $20 \mathrm{~m} 100 \mathrm{~m}$

- Stream

O MRS station

- Soil profile analysis

- Meteorological station

- Rain gauges

- H flume

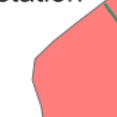

Figure 2: Pedological map and geomorphological characteristics of the Strengbach catchment.

\subsection{Hydrological and meteorological data}

The Strengbach catchment has been monitored since 1986 by the Observatoire HydroGéochimique de l'Environnement (OHGE, http://ohge.unistra.fr; CNRS/University of Strasbourg). The hydro-meteorological data sets collected during the last 30 years provide a unique material for studying the hydrological functioning of small mountainous headwater catchments (Pierret et al., 2018). They allow for evaluating the impact of climate change on various hydrological and vegetation processes and discussing issues related to sustainability of water resources in forested, mountainous environments (Beaulieu et al., 2016).

Two meteorological stations (one located on the northern crest and the other close to the stream outlet of the catchment) monitor the rainfall, temperature, and relative humidity. The upper station also monitors the global radiation, wind speed, and snow cover thickness. Seven additional rain gauges render information on the variability of the rainfall spatial distribution. The average precipitation over the catchment is estimated from the value measured at the northern crest and then multiplied by a corrective factor determined by analyzing the relationships between the rain gauges spatially distributed over the catchment (Viville et al., 1993; Pierret et al., 2019). The evapotranspiration is estimated as being the atmospheric demand evaluated by the Penman formula (1948).

An $\mathrm{H}$-flume continuously gauges the stream discharge at the outlet (Fig. 2). Other flumes are placed along the main stream or along secondary tributaries and are used to collect intermittent local data fortnightly. Among those, the RAZS (standing for "Ruisseau en Amont de la Zone Saturée", ie: upstream the saturated zone) flume monitored the discharge continuously during a few months for a temporary experiment in 1996 (Fig. 2). Nine boreholes were drilled in 2012 and 2013 with a depth varying between 15 and $120 \mathrm{~m}$, mainly for sampling rock cores. These boreholes are deep enough to intercept a few fractures in the bedrock, which renders the water levels monitored in these open 
boreholes unable to reflect hydraulic pressure heads in the active shallow porous aquifer of the catchment.

The local climate is of temperate oceanic mountainous type. The analysis of OHGE data in the 2007-2016 period shows a mean annual temperature of $6{ }^{\circ} \mathrm{C}$ with mean monthly temperatures varying between $-2{ }^{\circ} \mathrm{C}$ and $14.5{ }^{\circ} \mathrm{C}$. The average raw precipitation amounts to $1340 \mathrm{~mm} . \mathrm{yr}^{-1}$ (intermittent snowfall occurs during two to four months in a year) with inter-annual variations from 1136 to $1594 \mathrm{~mm} . \mathrm{yr}^{-1}$. The mean annual potential evapotranspiration is estimated at $588 \mathrm{~mm} . \mathrm{yr}^{-1}$ with values ranging between 544 and $637 \mathrm{~mm} \cdot \mathrm{yr}^{-1}$. The Strengbach catchment collects different sources and streamlets, and the mean flow rate at the outlet of the main stream is $666 \mathrm{~mm}$. $\mathrm{yr}^{-1}$ with inter-annual variations between 584 and $904 \mathrm{~mm} . \mathrm{yr}^{-1}$. To close the water budget, the volumes extracted for the water supply of the Aubure village should also be accounted for as they represent approximately $14 \%$ of the total annual volume exiting the system by the stream. This annual average withdraw for water supply is $92 \mathrm{~mm} \cdot \mathrm{yr}^{-1}$ and varies between 72 and $133 \mathrm{~mm} \cdot \mathrm{yr}^{-1}$.

\subsection{MRS measurements}

Using the mono-channel MRS system Numis ${ }^{\text {plus }}$ device from IRIS instruments, we performed 32 MRS measurements. Two campaigns in April and May 2013 investigated 23 sites. Eight-shaped loops were used as previous tests and showed the ability of such a geometry to reduce the ambient noise (Boucher et al., 2015). The eight-shaped loops were made of two squares, each being of 37.5 or $40 \mathrm{~m}$ on each side, depending on the available cables. Thus, the maximum sounded depth was of about $40 \mathrm{~m}$ and the information on the water content vertical distribution collected in the datasets was expected to be relatively coarse. Indeed, no information was available about the groundwater circulation at the time the MRS measurements were carried out. Therefore, the strategy was simply to record soundings able to provide an overall information on the water content distribution. With noises measured before the acquisition and not synchronously, interpretation methods using remote but synchronous noise measurements were inapplicable (Dalgaard et al., 2012). However, eight-shaped loops with 200 to 300 stacks were used and some recent tests in the field with a multi-channel MRS system did not show any improvement. Thus, the eight-shaped loop strategy remained the most efficient in this specific catchment compared with filtering based on remote noise measurements. Acquisition protocols corresponding to either free induction decay (FID) or spin echo (SE) signals were collected, depending on the station. Indeed, the occurrence of magnetic minerals associated with past hydrothermal activity on the northern slope allowed some SE recordings in this part. Nevertheless, we decided to use only FID signals in this study because of their higher amplitude and their availability at all MRS stations. Finally, only 16 data sets (stations) were kept, covering fairly well the southern part of the catchment, while only a few stations remained useful on the northern hillside (Fig. 3). In addition, for the selected data sets, only measurements performed with the weaker injected pulses ( $q<=2000 \mathrm{~A}$.ms ) were kept, because the signals of higher pulse moments were not sensitive enough to the shallow distribution of the water content. Data processing was done with the SAMOVAR-11x4 software, a package developed at the Institut de Recherche pour le Développement (IRD, France). 


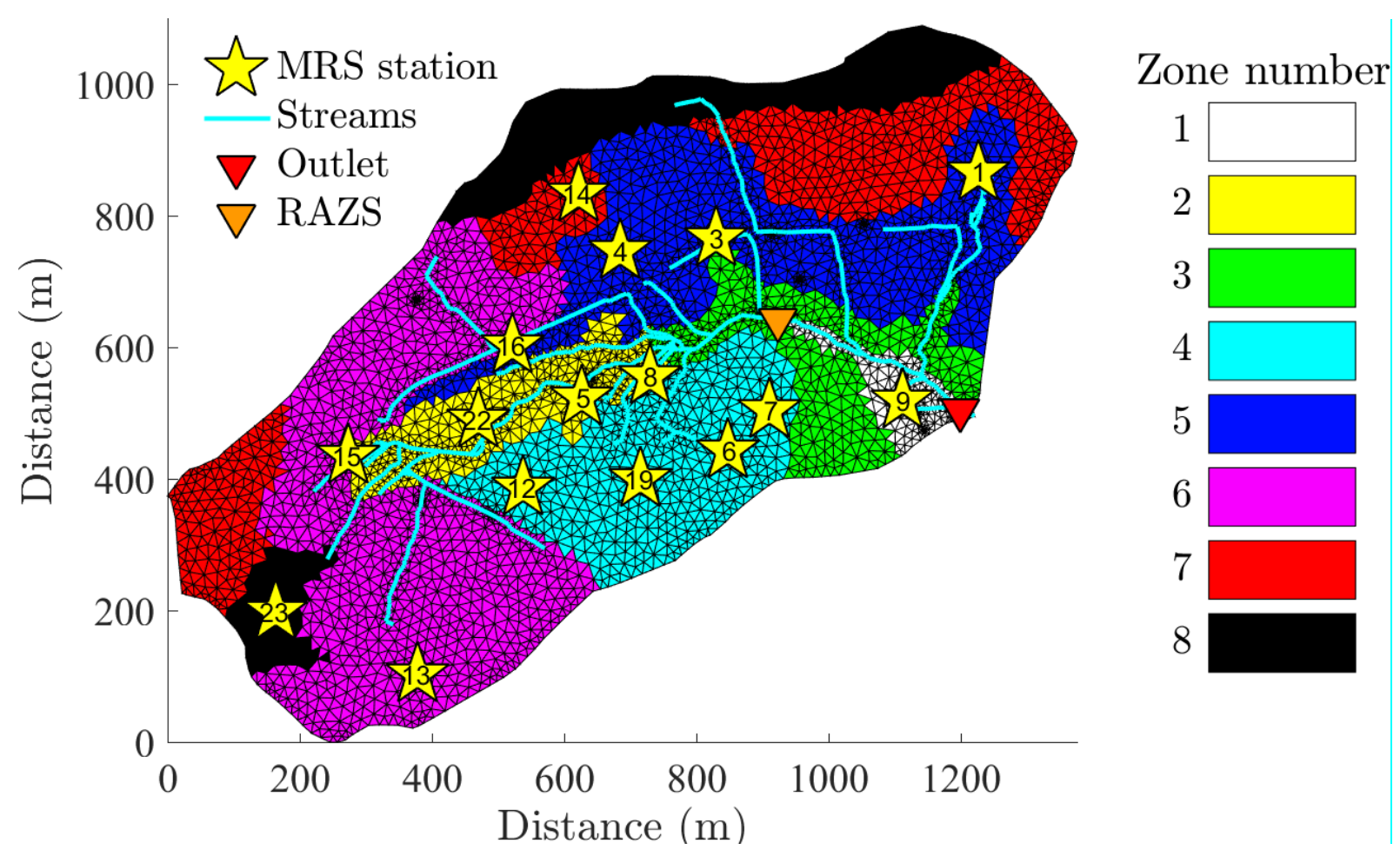

Figure 3: Meshing and zonation of the hydrological model coupling subsurface flow and one-dimensional surface routing network (in light blue).

As mentioned in Section 2, the measured signal was strongly affected by environmental noise, mainly because the MRS signal amplitude was weak (with a maximum amplitude of about $50 \mathrm{nV}$ for our study site characteristics). After a time out of $40 \mathrm{~ms}$, the acquisitions were recorded with a sampling rate of 2 ms last between 205 and 466 ms. However, to compute $\mathcal{A}_{\text {mes }}(q)$, we applied the time integration only over the first $162 \mathrm{~ms}$ (after the time out) of the recording because the final measurements showed strong fluctuations due to the exponential decrease of the signal that was rapidly vanishing over time and much more sensitive to the ambient noises at long acquisition times

A previous analysis of the MRS measurements rendered a qualitative depiction of the subsurface water volume distribution in the catchment (Boucher et al., 2015; Pierret et al., 2018). The map of the water volume concealed in the weathered layer of the system shows some variability strongly correlated with the pedologic zonation (Fig. 2). The gneissic and clayed rock materials of the northern crest might prohibit the detection of subsurface water by MRS measurements (Boucher et al., 2015). On the northern hillside, the shallow subsurface is made of fissured/fractured granites altered by intense past hydrothermal circulations. There, the estimated water volume is intermediate and might feed perennial flow overtime (Boucher et al., 2015). The southern hillside, which is less altered (Fichter et al., 1998b), shows smaller water content with a drier vadose zone less prone to infiltration. Finally, the water content is higher underneath the wetland in the downstream part of the catchment and under the flat colluvium zone, which would be the thickest porous subarea of the catchment (Boucher et al., 2015).

\subsection{Parameters set up given the catchment characteristics}

In this study, the 2-D mesh used for the subsurface flow computation in NIHM is refined close to the streams to model accurately the surface and subsurface coupling (Fig. 3). The mesh is also refined close to the MRS stations to provide accurate information on the subsurface water content distribution. The 2-D mesh is made of 10249 triangular elements delineated between 5260 nodes. The 1-D stream network is extended upward to the actual stream path to form the water routing associated with the logging roads since they behave intermittently as brooks. The 1-D mesh is drawn by 828 
Lesparre et al., 2020, J. of Hydrol.

segments joining 821 nodes. Specifically, for the application to the Strengbach catchment, NIHM was parameterized by following a delineation in zones derived from the pedological map (Fig. 2 and 3). Hydraulic parameters within each zone are uniform and the characteristics of these zones are reported in Table 1. The acrisols of weathered slopes that present similar pedologic characteristics (in orange in Fig. 2) are distinguished according to their location on either the northern or the southern hillsides of the catchment. Indeed, those two hillsides are distinguished in terms of thickness and porosity of aquifer layers because of their different level of alteration (Fichter et al., 1998b). The regions corresponding to the narrow corridors of brown earth (in green in Fig. 2) are overlooked.

Table 1: Soil characteristics and locations of the zones patterned from the pedological map. The numbering of the zones is that of Fig.2.

\begin{tabular}{|c|l|l|}
\hline Zone & \multicolumn{1}{|c|}{ Soil } & \multicolumn{1}{|c|}{ Location } \\
\hline 1 & Gleysols, permanently or seasonal water saturated & Valley bottom \\
\hline 2 & Colluviums & Spring of the main stream \\
\hline 3 & Ranker & Valley bottom \\
\hline 4 & Acrisols weathered slope & Southern slope \\
\hline 5 & Acrisols weathered slope & Northern slope \\
\hline 6 & Acrisols & Convex slope close to crests \\
\hline 7 & Acrisols & Crest zones \\
\hline 8 & Acrisols & Crest zones \\
\hline
\end{tabular}

The water content is extracted from the NIHM 3-D maps in the vicinity of each MRS station at the time the MRS data were acquired. The water content values are extracted inside a vertical cylinder of $40 \mathrm{~m}$ diameter centered on each MRS station. Then, the water content are averaged to build a 1-D model of water content $\theta\left(z^{\prime}\right)$ varying with the depth $z^{\prime}$ below ground level. From this $\theta\left(z^{\prime}\right)$ model, the MRS signal is computed as described in Section 2 before being compared with field measurements.

The exploration of the MRS data sensitivity was limited to two main parameters of NIHM: the aquifer thickness normal to the topographic surface and the porosity, which is considered as equivalent to the saturated water content $\theta_{s}$. Several exploratory calculations were performed to estimate the volume of the aquifer required to simulate the outlet flow rate dynamic of this very reactive catchment. For example, a thin single-layer aquifer with a uniform porosity of $8 \%$ is able to reproduce the outlet flow rate fairly well. The thickness of the single layer can vary over space between 2 and $8 \mathrm{~m}$, and more than 20 single-layer models evenly fit the outlet flow rate with a KGE $>0.88$, a NSE $>0.87$ and a RMSE $<6.961 . \mathrm{I}^{-1}$. These examples illustrate the equifinality issue encountered when only the outlet flow rate is available. By contrast, the single-layer models fail to correctly reproduce the MRS data. In particular, station 22 shows a $\chi^{2} \geq 10$, irrespective of the parameter values, when representing the subsurface with a single layer (Fig. 4 a). 

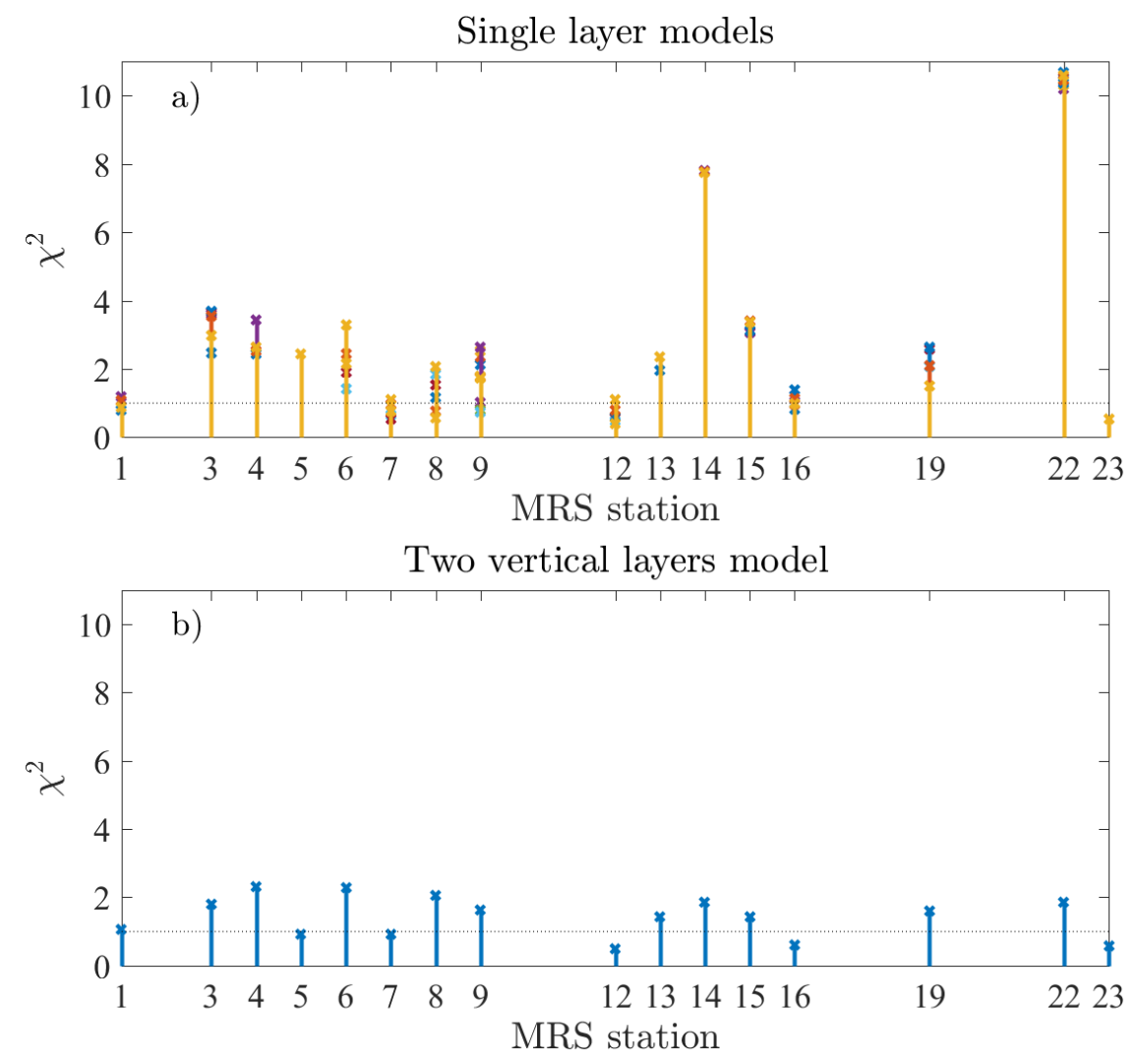

Figure 4: $\chi^{2}$ values for each MRS station for single layer models (a) and for a two vertical layers model (b).

The MRS measurements are in fact very sensitive to the contrast in water content between a thin (one meter or so), very superficial, strongly altered zone of soil and, beneath, a deeper layer showing a porosity strongly decreasing with depth corresponding to the saprolite. Thus, in each zone of the catchment, we sought the thickness and the porosity for a two-layer model as depicted in Fig. 5. The superficial layer represents the soil that might be relatively thin but with higher porosity than the underlying saprolite susceptible to be thicker but with smaller porosity (Fig. 5). This type of geometry for the shallow subsurface has often been evoked in other mountainous hard rock sites (Befus et al., 2011; Holbrook et al., 2014, 2019; Orlando et al., 2016; Flinchum et al., 2018a). The other parameters of NIHM, reported in Table 2, were prescribed as uniform values over the whole catchment. Except for the $K_{\text {sat }}$ parameter, all the other parameters in Table 2 do not have a strong effect on the model outputs. The values of $\alpha$ and $n$ parameters in the Van Genuchten model are chosen close to that discussed in a hydrological modeling inter-comparison performed by Maxwell et al. (2014). The $K_{\text {sat }}$ value is fixed to limit the space of parameters to explore. 
Lesparre et al., 2020, J. of Hydrol.

Table 2: Values of prescribed hydraulic parameters for all zones of the catchment in the hydrological simulations by NIHM.

\begin{tabular}{|r|c|c|}
\hline Parameter & Symbol & Value \\
\hline Saturated hydraulic conductivity & $K_{\text {sat }}$ & $1 \cdot 10^{-4}{\mathrm{~m} . \mathrm{s}^{-1}}^{-1}$ \\
\hline Specific storage capacity in the saturated zone & $S_{\text {sat }}$ & $1 \cdot 10^{-8} \mathrm{~L}^{-1}$ \\
\hline Parameter related to the mean pore size & $\theta_{r}$ & 0.01 \\
\hline Parameter related to the pore size distribution & $\alpha$ & $1.5 \mathrm{~m}^{-1}$ \\
\hline
\end{tabular}

As already mentioned, NIHM outputs render an estimate of the water content in all the active layers constituting the aquifer from the surface to the bedrock. However, some water could be present below the soil and saprolite layers (the active aquifer of the catchment), inducing a signal recorded in the MRS raw data. For example, water in the weathered bedrock could be detected by MRS even if this water contributes to neither the very transient superficial hydrology nor the stream flow rate. With this in mind, we choose to allow some degree of freedom to the fit of MRS data by considering the eventual existence of water content in various layers beneath the shallow aquifer modeled by NIHM. The bottom limit of this deeper medium is set to $30 \mathrm{~m}$ below the ground surface, and the deeper medium is divided into 6 layers between the bottom of the NIHM aquifer and the lower limit (Fig. 5). $\theta\left(z^{\prime}\right)$ in the three shallower layers of the weathered bedrock might range between 0 and 0.005 , while the three deeper layers $\theta\left(z^{\prime}\right)$ might range between 0 and 0.03 . The first three layers in the weathered bedrock with very small water content help both the MRS estimates and the hydrological modeling to clearly delineate the interface between the active shallow aquifer and the weathered bedrock. The three deeper layers in the weathered bedrock with higher (but still small) water content help to retrieve water concealed in depth as evidenced by the first analysis of the MRS datasets (Boucher et al., 2015). As NIHM only provides estimates of the water content $\theta(z)$ in the shallow aquifer, the values of $\theta(z)$ in the six underlying bedrock layers are unknown. Those values are sought during the least-square inversion in the step 5 of the workflow that also looks for two values of $T_{2}^{*}(z)$ : one assigned to the shallow aquifer modeled by NIHM and the other to the six layers of the weathered bedrock (Fig. 5). 


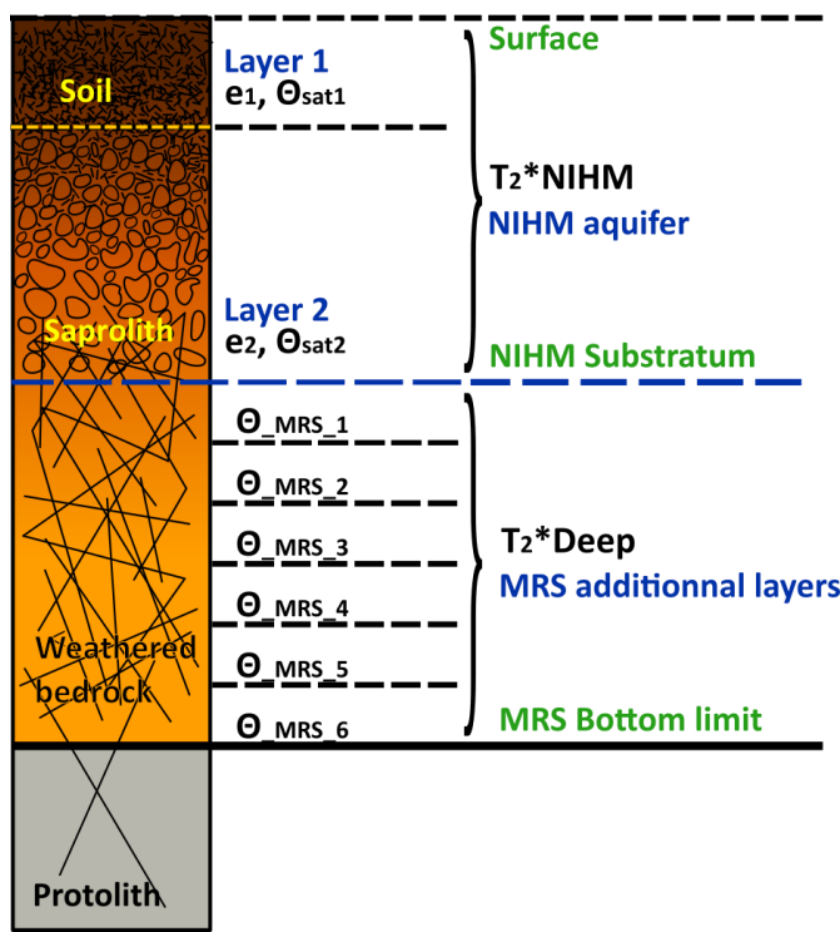

Figure 5: The subsurface layers of the Strengbach catchment for both the hydrological model NIHM and the simulation of MRS signals. The aquifer in NIHM is made of the two superficial hydraulically active layers corresponding to the soil and the saprolite (heavily weathered hard rock). For both, the thickness (e) and the saturated water content ( $\theta(z)$ ) are explored to fit the MRS data. Eventual occurrence of water beneath the aquifer is accounted for by six additional layers of prescribed uniform thickness in the weathered bedrock. These layers are overlooked by the hydrological model, and only the water content is sought for MRS simulations to fit data. Only two values $T_{2}^{*}$ of the relaxation time are determined: one in the active aquifer, and one for the six layers of the weathered bedrock.

MRS data reflect the state of local water content in the subsurface, but for systems flowing rapidly, such as the hillslopes of the catchment, this local state might also depend on the water circulation in regions located upward and downward from the acquisition point. In other words, the water locally stored beneath the MRS stations depends on the hydraulic properties of the upward and downward regions. As an example, stations 5 and 9 are shown to be sensitive to the hydrodynamic parameters of the zones located upward. Therefore, when seeking the model parameters in NIHM to fit MRS data, the search is first carried out for the contributing regions represented by the crests and the upper parts of the hillsides. Then, the parameters are explored downward, toward the valley draining the whole catchment. This procedure is intended to progressively fit the whole MRS data set together with the outlet flow rate of the stream in the valley.

\section{Results and discussion}

\subsection{Hydrogeophysical data fit}

An example of the set of parameters fairly well fitting the MRS data and the outlet flow is given in Table 3. Presently, no complementary geophysical data are available to validate this set of parameters. Loggings from six boreholes confirm the observed tendency of a soil thickness relatively homogeneous around $1 \mathrm{~m}$ while the saprolite thickness is more susceptible to vary with higher values in zone 2. Other sets of parameters with values close to those presented in Table 3 could also reproduce this data set. However, an MRS data set with a reduced noise level and a higher sensitivity to the shallow medium is required to perform a quantitative study of the parameters set confidence interval as discussed below. The resulting porosity values might seem low in both the soil and saprolite layers, sometimes with values as low as 0.1 in the soil and 0.02 in the saprolite (Table 3). It is worth noting that they correspond to an average value of the porosity in each layer. Moreover, they reflect 
the effective porosity since the hydrological model only takes into account the porosity that enables water circulation. This is consistent with the MRS signal that is mostly influenced by the water contained in the effective porosity. The quality of fitting between data and simulations is reported for each MRS station $\left(0.5 \leq \chi^{2}<2.5\right.$ Fig. $4 \mathrm{~b}$ ) and for the outlet flow rate (KGE=0.86; RMSE $=6.08 \mathrm{I}^{-\mathrm{s}^{-1}}$; NSE= 0.91, Fig. 6). A longer period is shown in Fig. 6 compared to the one used for calibration tests of NIHM (February 1, 2013, to May 31, 2013). The idea is to show the forcing variations until the beginning of September 2013 because it is also discussed below of synthetic tests conducted to estimate the MRS signal until that date. Simulations with the same set of parameters were also run: (a) over a few months during spring 1996 when the stream flow rate was also monitored continuously at the RAZS station (Fig. 3), and (b) between the beginning of September 2008 and the end of August 2016. Such simulations show a fair agreement with field flow rate measurements as a KGE value of 0.7 is estimated at RAZS and at the outlet for the 1996 period. For the 2008-2016 simulation, the KGE is 0.84 .

Table 3: Fitted model parameters (porosity and thickness of the two aquifer layers) of the best hydrological simulation of the catchment (numbering in the table is that of zones in Fig. 2).

\begin{tabular}{|c|c|c|c|c|c|}
\hline Zone & Total & Thickness & Thickness & Porosity & Porosity \\
number & thickness $(\mathrm{m})$ & layer 1 $(\mathrm{m})$ & layer 2 $(\mathrm{m})$ & layer 1 $(-)$ & layer 2 $(-)$ \\
\hline 1 & 10 & 2 & 8 & 0.5 & 0.03 \\
\hline 2 & 14 & 1 & 13 & 0.3 & 0.03 \\
\hline 3 & 4 & 1.5 & 2.5 & 0.6 & 0.02 \\
\hline 4 & 3 & 1 & 2 & 0.3 & 0.02 \\
\hline 5 & 7 & 1 & 6 & 0.1 & 0.02 \\
\hline 6 & 4 & 0.5 & 3.5 & 0.1 & 0.02 \\
\hline 7 & 2 & 1 & 1 & 0.5 & 0.02 \\
\hline 8 & 3 & 0.5 & 2.5 & 0.2 & 0.05 \\
\hline
\end{tabular}


a)

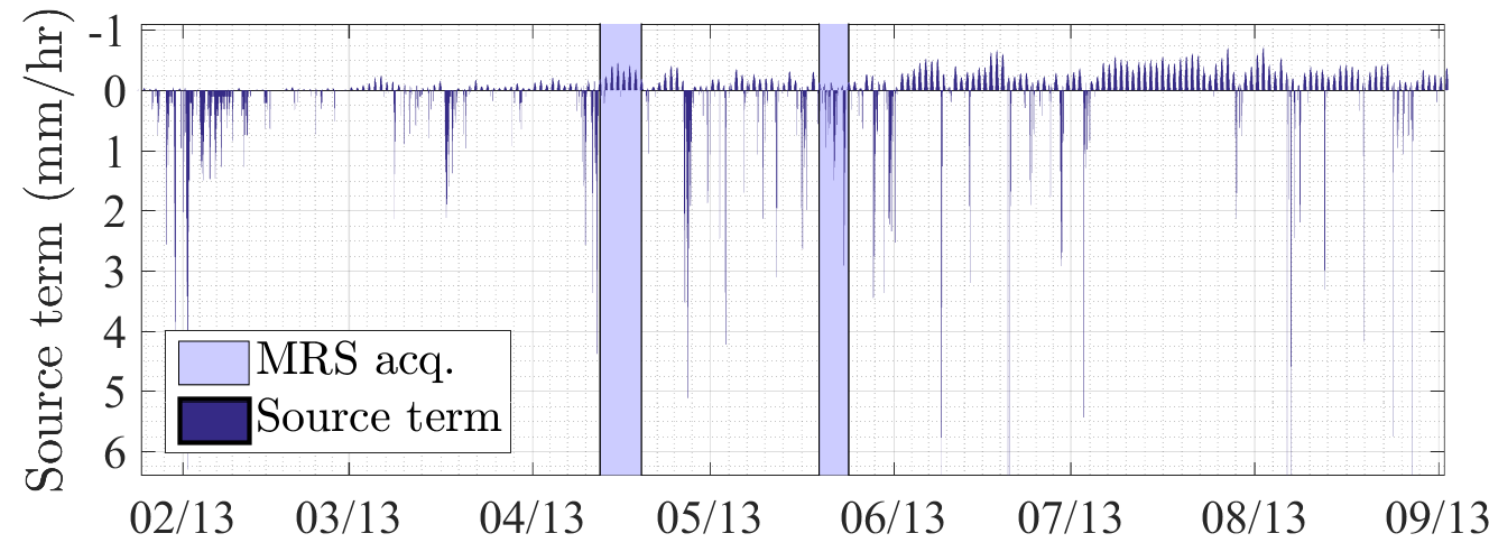

b)

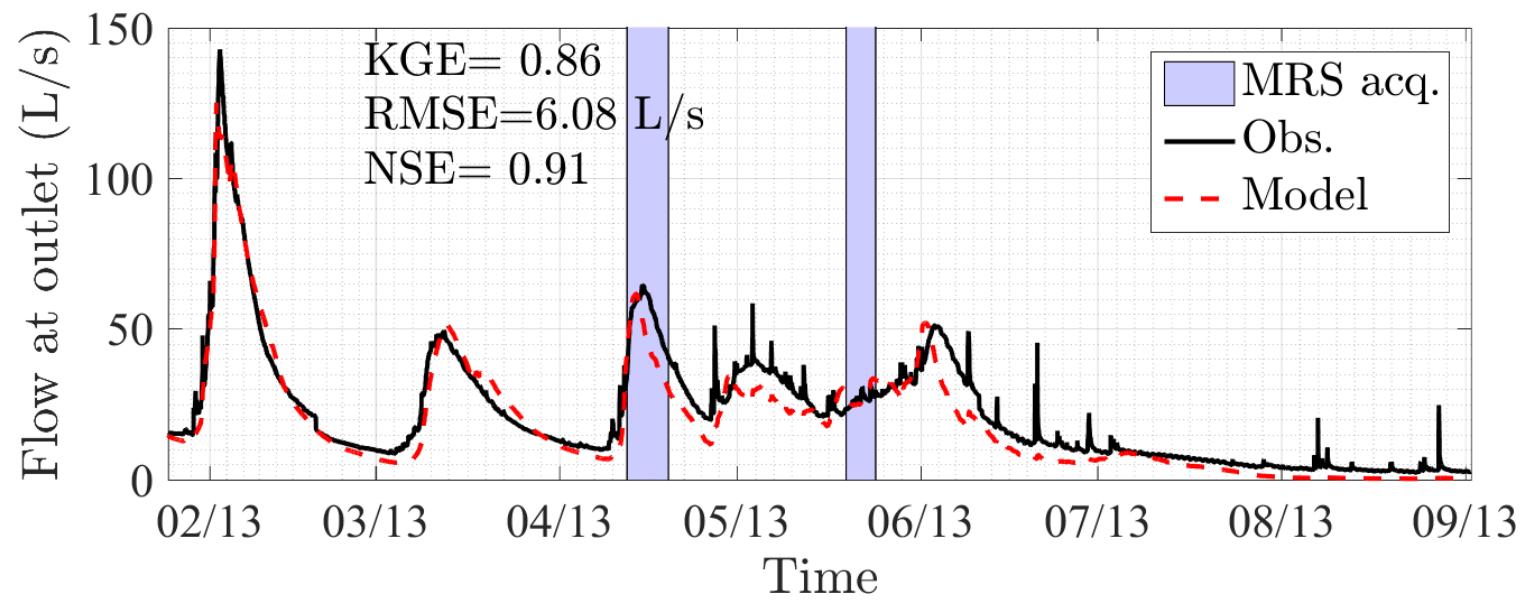

Figure 6: Top, source term (rain minus evapotranspiration) during the period extending from January 25 to September 2, 2013. Down, measured (solid black curve) and estimated (dashed red curve) stream flow rate at the outlet of the catchment. The periods of MRS acquisitions are highlighted in the blue bars.

The porous space available for subsurface flow circulation corresponding to the selected set of parameters is illustrated in Fig. 7, mapping the porous volume in the subsurface per unit of surface area of the aquifer. This quantity is simply estimated by multiplying the thicknesses of the subsurface layers by their corresponding porosity $\theta_{s}$. The state of the water content at the date of the first MRS acquisition, the $12^{\text {th }}$ of April 2013, is mapped in Fig. 8. The water volume at that time is strongly patterned by the porous space available (Fig. 7). The boundaries of the zones dividing the catchment (Fig. 3) are emphasized by strong variations of the concealed water volume because of the abrupt variations of the aquifer thicknesses. Zone 2 , which is located upstream from the main springs, shows a high water volume despite its lower porous space compared with zones 1 and 3 . This observation can be explained by its small slope, allowing the area to better store water than an area of steep slopes where water flows rapidly under gravity-driven forces. A disparity is observed between the northern and southern slopes of the catchment as witnessed by zones 4 and 5 . Despite their similar available porous space, the southern slope (zone 4) shows a slightly higher water volume. Here again, this can be explained by the steeper slopes of zone 5 that favor downward drainage. 


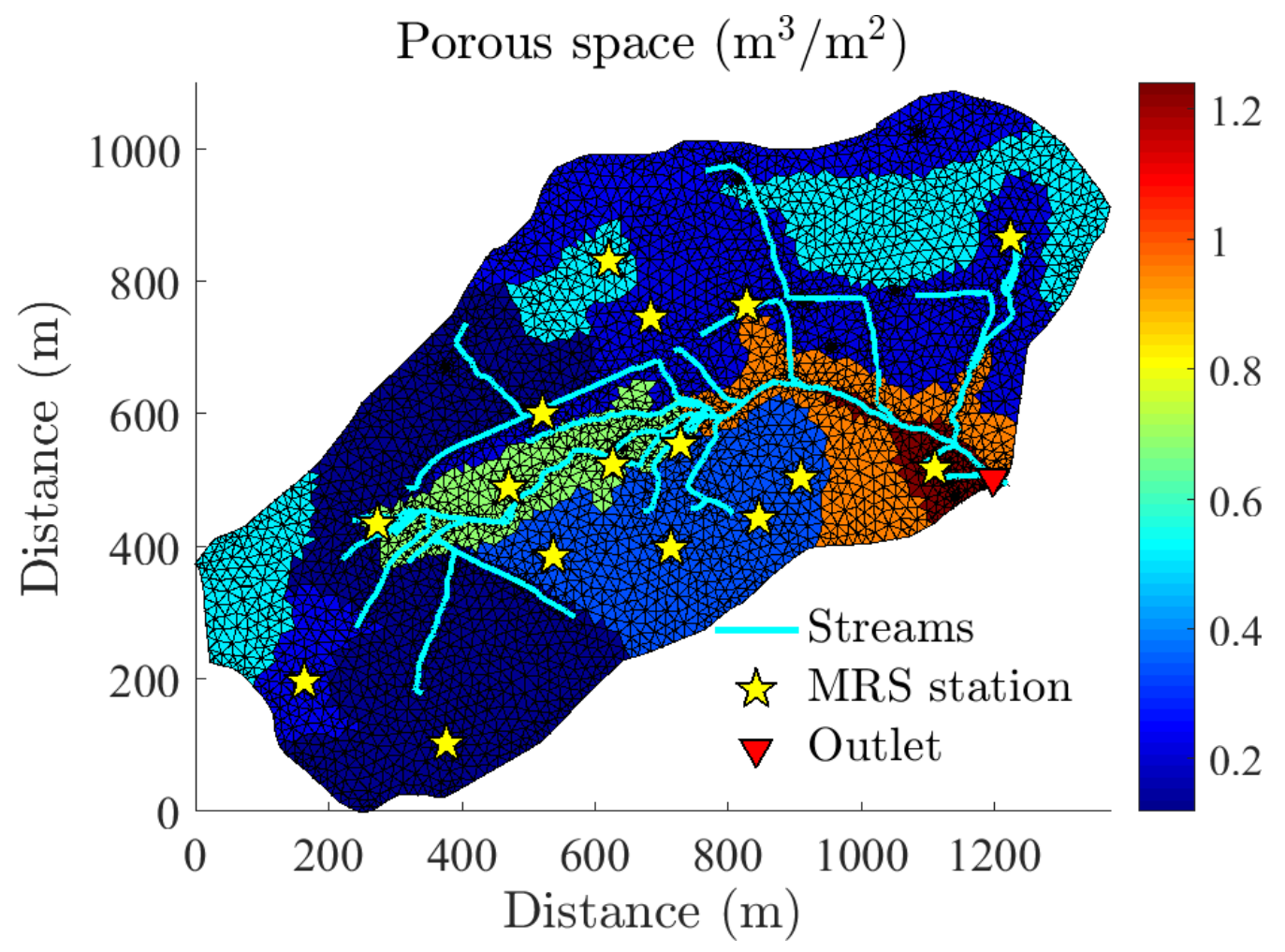

Figure 7: Porous space (in $\mathrm{m}^{3}$ per unit surface area $\left(\mathrm{m}^{2}\right)$ of the aquifer) available for subsurface water circulation. The quantity corresponds to the sum of thicknesses of the subsurface layers multiplied by their corresponding porosity.

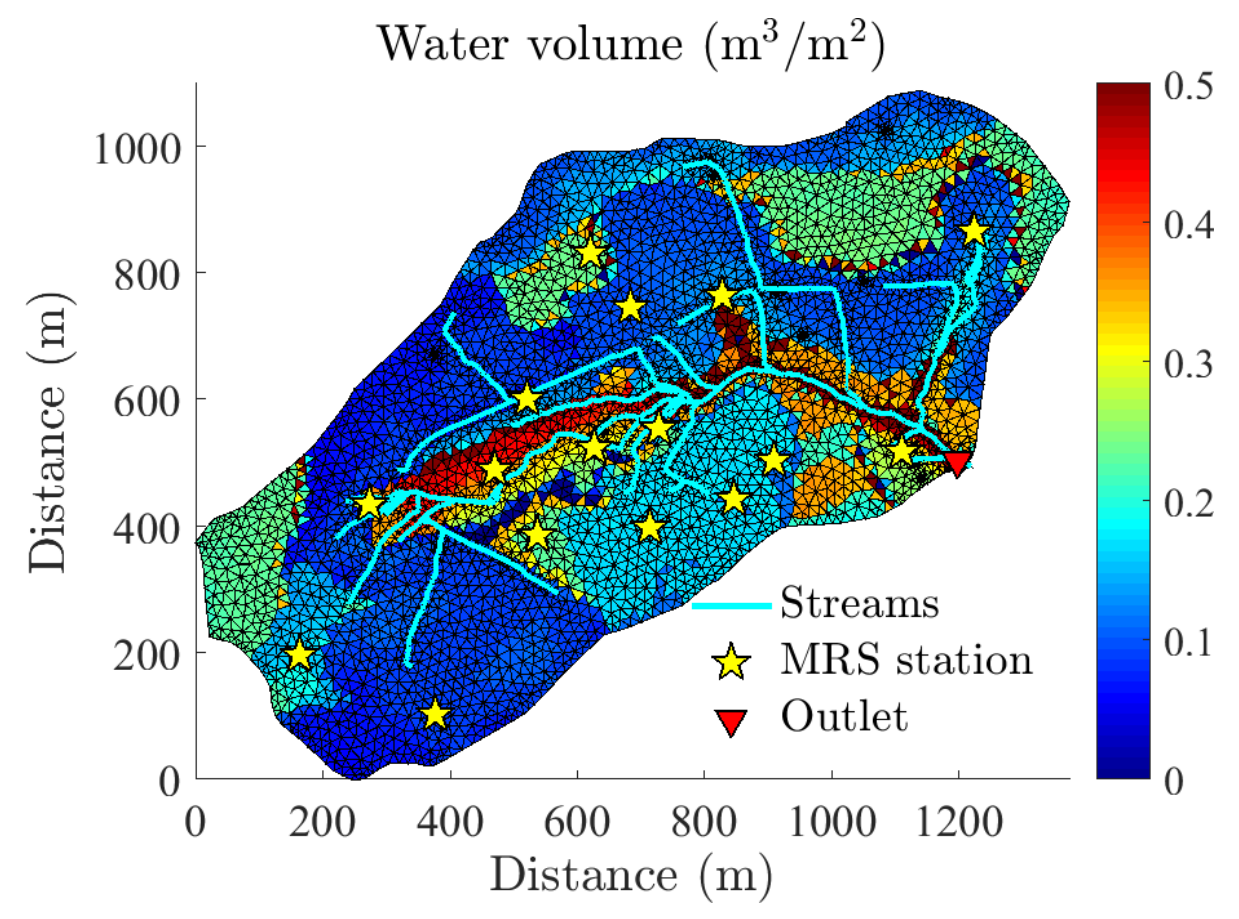

Figure 8: Water volume (in $\mathrm{m}^{3}$ per unit surface area $\left(\mathrm{m}^{2}\right)$ of the aquifer) estimated by the NIHM simulation for April 12, 2013, i.e., the date of the first MRS data acquisition.

The water content estimated by NIHM beneath each MRS station is strongly patterned by the zone in which the station is located (Fig. 9). All MRS stations within a given zone respond similarly in terms of the water content modeled by NIHM, with the exception of station 8 , which appears as an 
outlier in zone 4 close to the boundaries of zones 2, 3, and 4. Except for stations 9 and 14, fitting the whole MRS data set requires the presence of water in depth (in the weathered bedrock) to reproduce the measurements (Fig. 9). Although the inversion lacks constraints to quantitatively evaluate the corresponding amount of water present in depth, we infer the presence of water in the weathered bedrock beneath the active shallow aquifer. It should be noted that deep water is not necessary to reproduce the amplitude and the variability of the outlet flow rate.
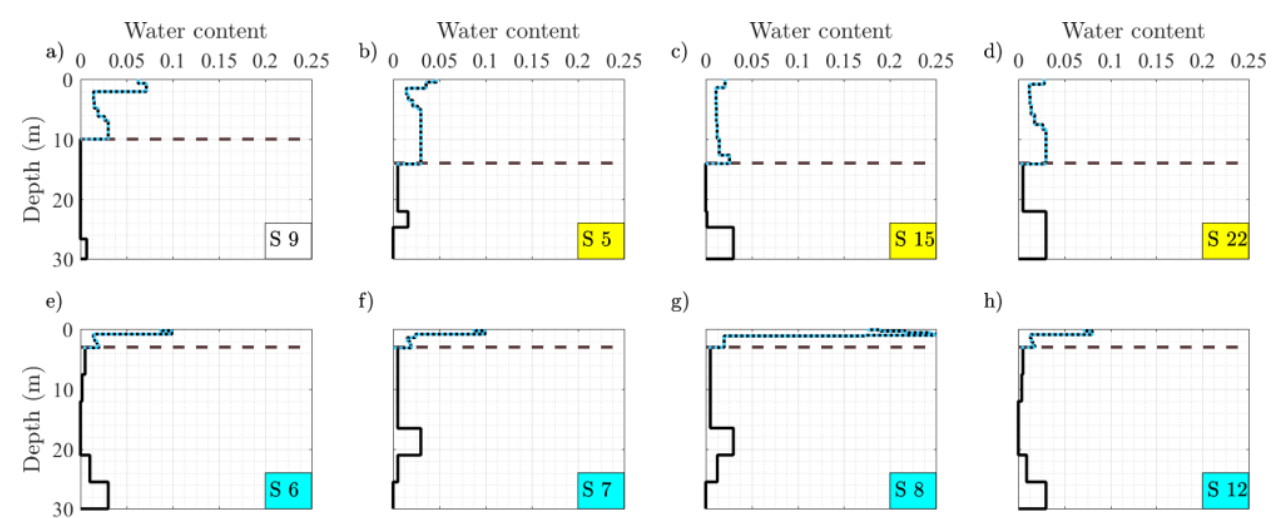

f)

g)

h)
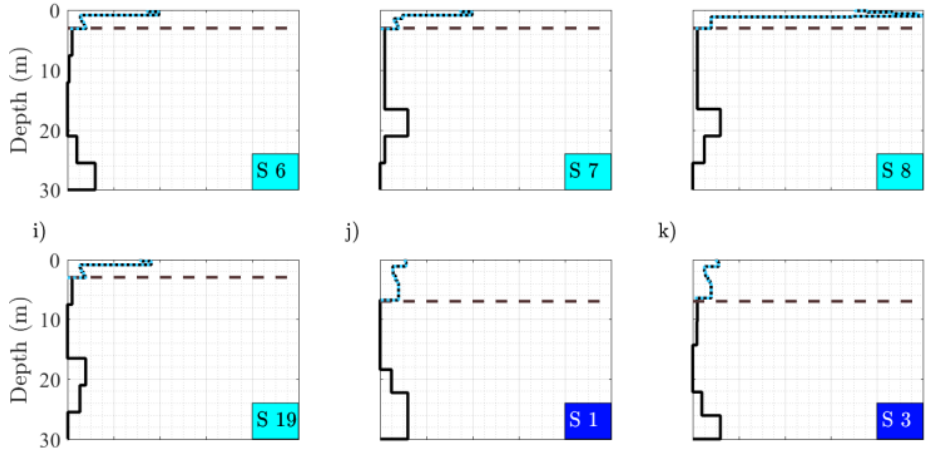

j)

k)
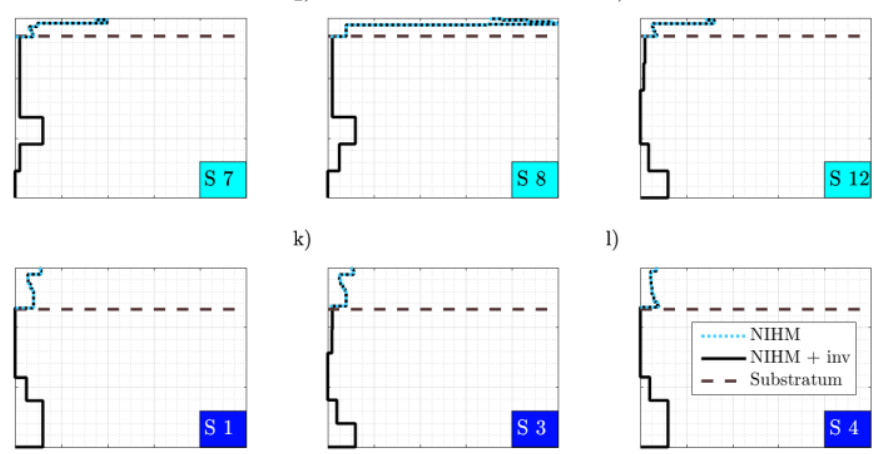

1)

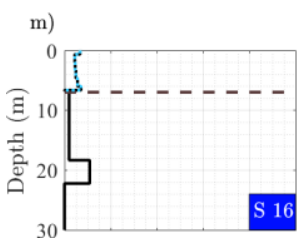

n)

o)
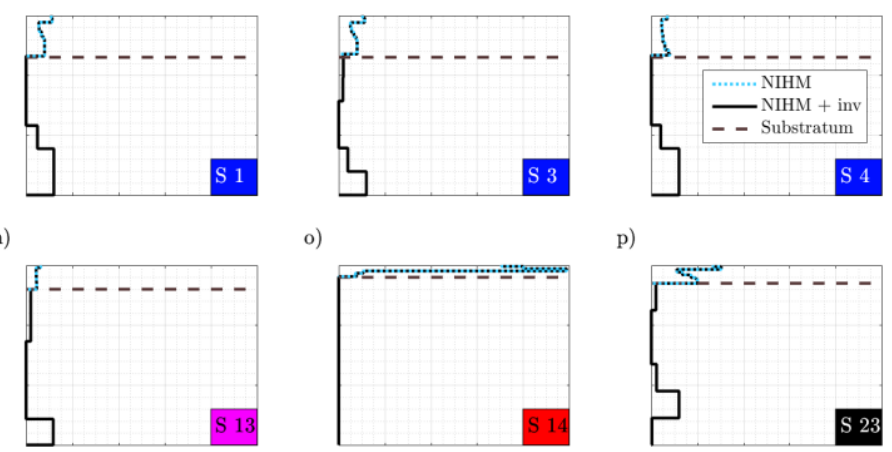

p)

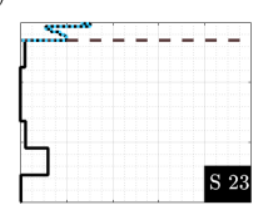

Figure 9: Water content in the aquifer [-] beneath each MRS station estimated by NIHM (blue). The water content (black curve) beneath the aquifer is set up to simulate the best MRS data corresponding to the highest pulses. The color codes of the squares in the bottom right corner of each plot are that of the zones dividing the catchment in Figure 3

The MRS data are in general explained by NIHM simulations (Fig. $4 \mathrm{~b}$ and 10), and despite the low water content and the noise level, the method provides constraints on the NIHM parameters. For example, two layers with contrasting thickness and porosity must compose the shallow aquifer to reproduce the MRS signal together with the outlet flow rate. MRS data also provide an insight into the spatial distribution of parameters, thanks to the local but spatially-distributed nature of the measurements. Now it has been confirmed that the active aquifer is very superficial, another set-up of MRS measurements could be useful to improve the parameter estimates. It is noteworthy that MRS data in the form they have been collected are of limited resolution in the shallow subsurface. In the absence of hydrological modeling, when MRS data were collected in 2013, the medium was sounded over several tens of meters in depth as is classically performed for a first acquisition in unconstrained aquifers. Synchronous-noise measurements using a remote loop could also help to reduce the noise level (Dalgaard et al., 2012). Finally, MRS data are not free from equifinality issues when seeking the porosity and the thickness of the watered layers. Thus, complementary information about the aquifer thickness and porosity are required to better constrain these parameters. The knowledge of the subsurface seismic velocity variations at the scale of the catchment could help in constraining the porosity distribution and, hence, the aquifer thickness diversity (Flinchum et al., 2018b). Similarly, we did not attempt to interpret the $T_{2}^{*}(z)$ values obtained in this study (see Table 2 in Lesparre et al., submitted) as it is very likely that they might be non-unique. Therefore, we do not consider that the various estimated values $T_{2}^{*}(z)$ could also reflect the spatial variations of the hydraulic conductivities in the catchment. Again, measurements adapted for superficial soundings and complementary 
information on the catchment structure would enable qualitative and quantitative interpretations of the $T_{2}^{*}(z)$ values.
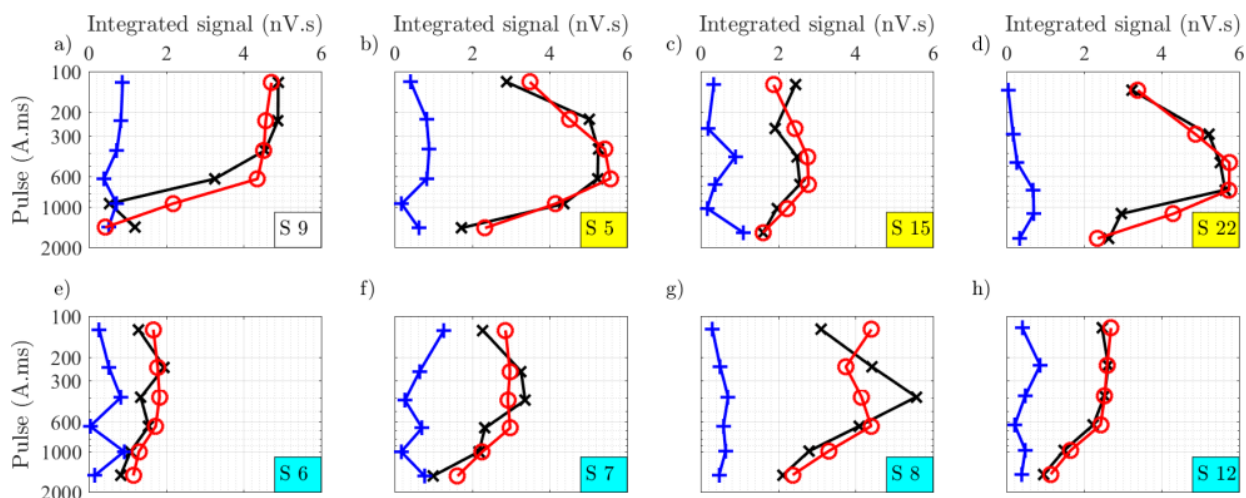

g)

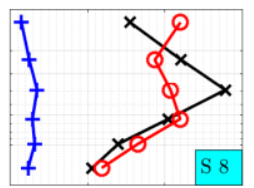

h)

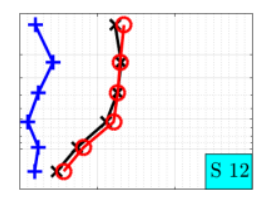

j)

k)
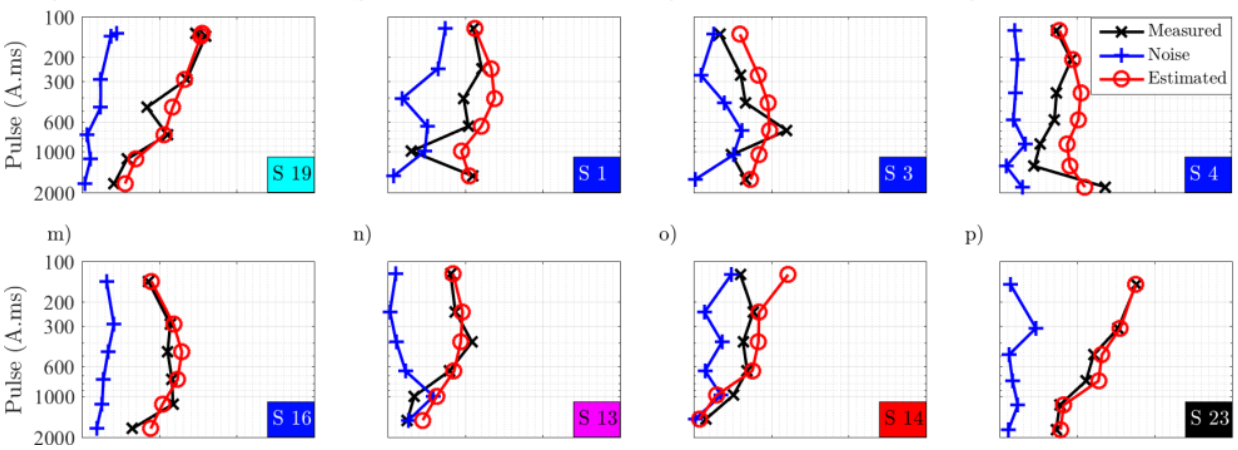

n)

o)

p)
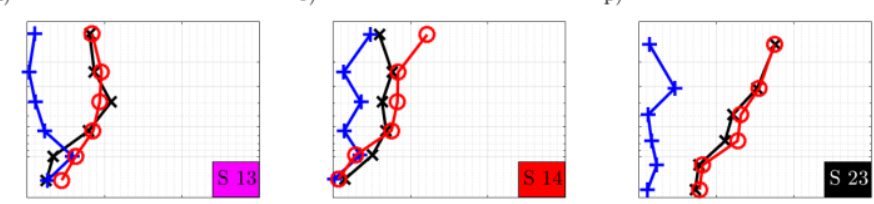

Figure 10: Measured (in black) and estimated (in red) MRS integrated signals for each station. The blue line is the measured (and integrated over time) noise recorded before MRS pulse injections. The color codes of the squares in the bottom right corner of each plot are those of the zones dividing the catchment in Figure 3

Although MRS is an acknowledged method for estimating the hydraulic conductivity $K$ (Legchenko et al., 2004; Mohnke and Yaramanci, 2008), we deliberately focused the exploration of parameters to the restricted set of aquifer thickness and porosity. The direct computation of $K$ from MRS is based on the MRS decay time distribution (Legchenko et al., 2004; Mohnke and Yaramanci, 2008). As stated above, the quality of the data used in our study is not good enough for providing reliable estimates of the MRS decay time and thus of $K$. Another way to seek $K$ could have been to add the parameter to the list of sought parameters to further reduce the MRS $\chi^{2}$, while keeping a fair fit of the flow rate data. However, $\chi^{2}$ values are already good and adding a sought parameter would have added under-determination to the calibration of the hydrological model. Here again, the acquisition of data with a higher signal to noise ratio and the use of complementary geophysical data are ideas to constrain $K$ values.

\subsection{Synthetic time-lapse exploration}

As discussed above, MRS data provide information constraining the calibration of the NIHM model by checking the compatibility of the water content estimated by the hydrological model against the MRS measurements. In turn, the calibrated model helps reveal fruitful information on the locations where MRS measurements might monitor dynamic processes of water content fluctuations at the scale of a rain event or at a seasonal scale. As an example, NIHM is run over the period extending from January 2013 to the end September 2013, and the simulated water content can be analyzed to check the sensitivity of MRS data to the water storage fluctuations. We assume that no storage fluctuations occur in the weathered bedrock beneath the shallow modeled aquifer, and we do not add the contribution of water in that layers. In any case, fixing a constant over time and positive water content 
value in the weathered bedrock would only generate a uniform shift of the MRS signal amplitude compared with the signal estimated when assuming that the weathered zone is dry.

The MRS signal errors used below correspond to those estimated from the measurements. Such errors give an insight into the MRS capacity to detect changes in water content. A first focus analyzes the strong rain event that occurred between the January 31 and February 10, 2013. Then, a seasonal analysis is attempted by comparing the water content at the end of this rainy event with three snapshots (separated by one month) in the flow rate recession period of July to September 2013.
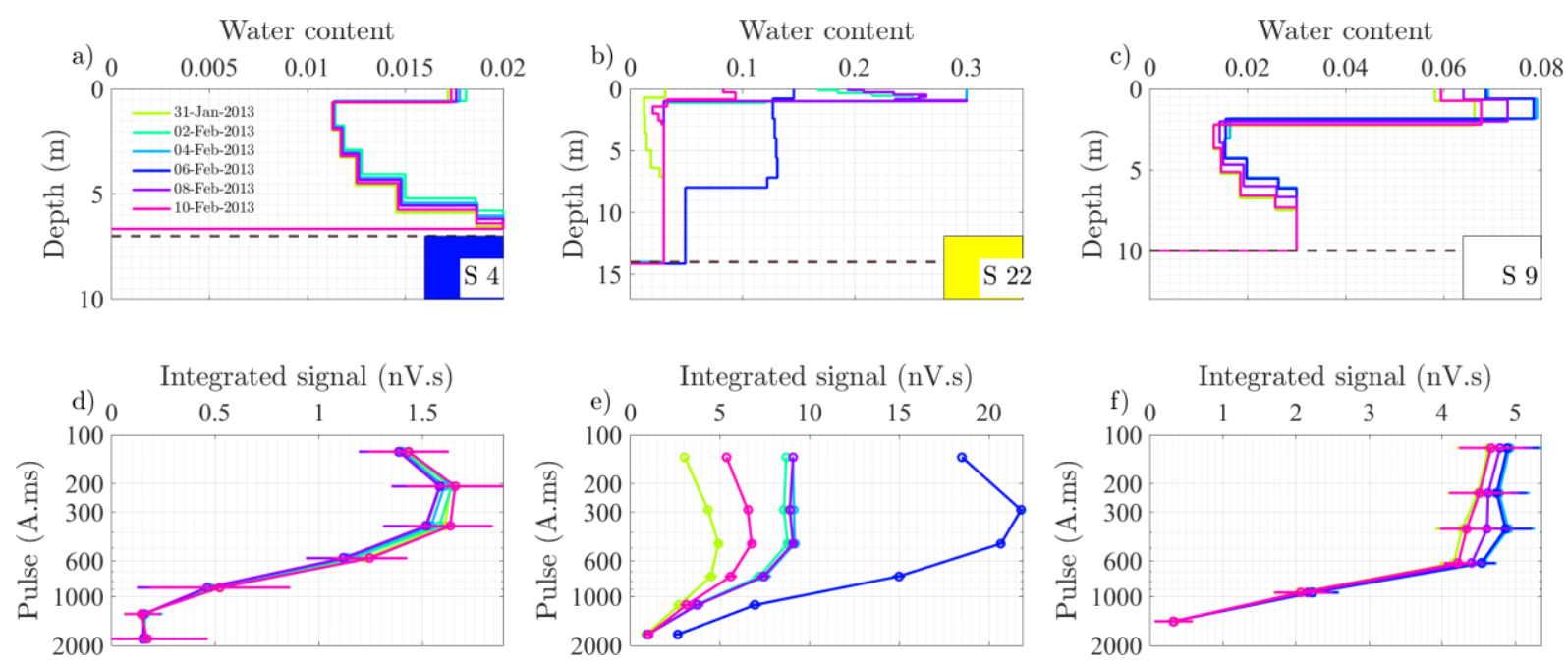

Figure 11: Influence of the time-varying water content in the aquifer on MRS signals at stations 4, 22, and 9 during a short rain event. Water contents in the weathered bedrock beneath the active aquifer are arbitrarily set to zero.
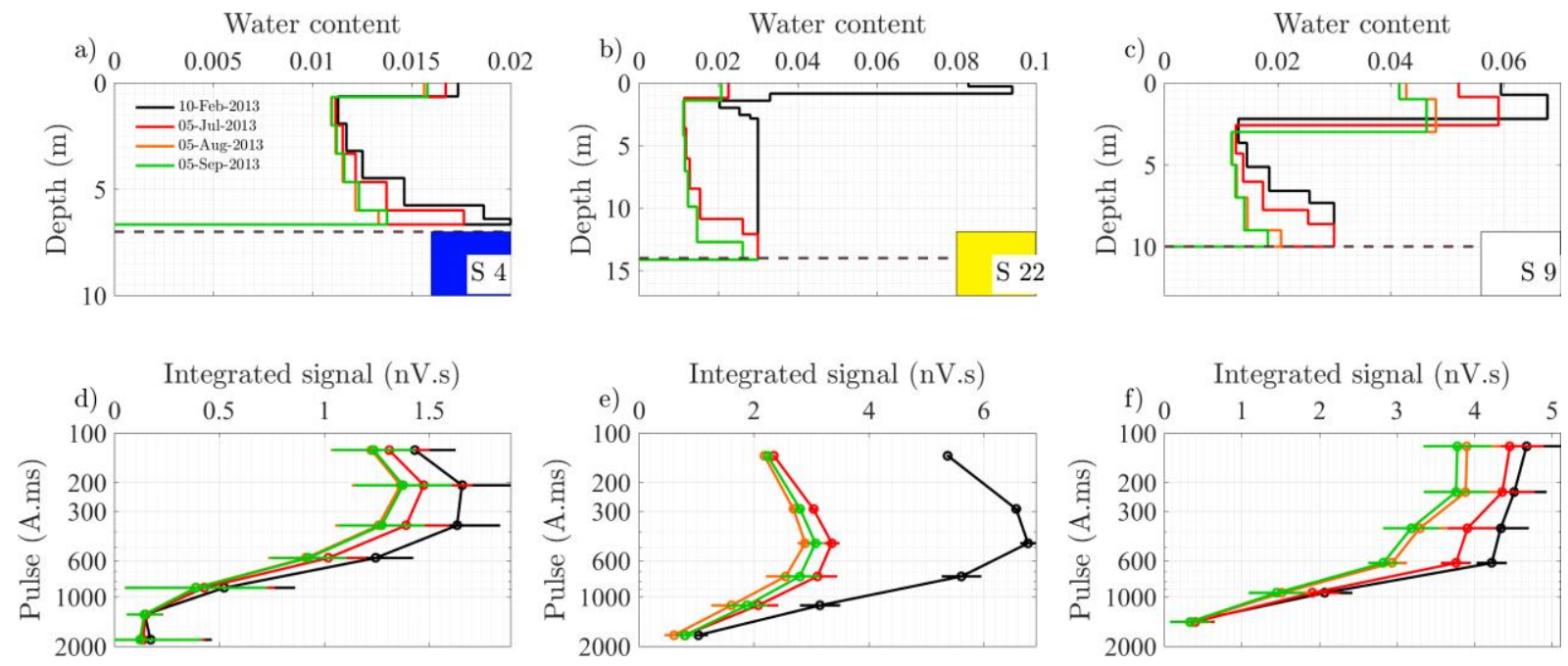

Figure 12: Influence of the time-varying water content in the aquifer on MRS signals at stations 4, 22, and 9 for snapshots over a seasonal period. Water contents in the weathered bedrock beneath the active aquifer are arbitrarily set to zero.

Conspicuously, for an MRS station located along a hillslope (station 4, Fig. 11 and 12, a, d), the rain event does not generate significant variations of the integrated MRS signal over time compared to the MRS error level. In fact, the steep slopes of the catchment are conducive to very rapid downward draining, prohibiting large water storage. Along the hillslopes, seasonal reductions of water inlets between winter and summer only induce a slight reduction of the water content in the deeper part of the aquifer (Fig. 12, a). The MRS signal should catch such variations because they span ranges slightly wider than the noise level (Fig. 12, d). That being said, MRS measurements still need to be carried out in the winter, right after a rain event, to confirm (or not) the dynamic of such seasonal behaviors, which 
are evidenced here by modeling only. On the other hand, a station located in zone 2 , above the storage region and upward from the spring of the main stream (station 22 Fig. 11, b, e), shows strong water content fluctuations within the short period of a rain event. Calculations for two days after any intense rainfall show a rise in subsurface water content, producing MRS signal variations well above the MRS error level. Even better, the MRS signal evolution over time is significant enough to monitor the water content dynamics with measurements acquired every second day, as illustrated in Fig. 11 e. Seasonal fluctuations of the water content also generate a meaningful disparity in the MRS signal between winter and summer. However, we note that the drainage remains relatively fast, meaning that during the summer recession period, the mean water content fluctuations generate close MRS signals but are still distinguishable. Finally, a station placed close to the outlet (station 9, Fig. $11 \mathrm{c}$, f), in the small wetland zone along the stream, is barely sensitive to water content variations related to a strong rain event. However, the MRS signal is more sensitive to seasonal fluctuations and even shows a significant decrease during the recession period (Fig. 12 c, f). Such simulations of MRS signals, based on simulated water content in the subsurface, have to be confirmed with repeated MRS measurements. At the very least, those types of calculations highlight the benefit of hydrogeological models to design relevant spatio-temporal duplication of MRS experiments that are particularly cumbersome to set up.

\section{Conclusions}

We show here the great potential of MRS data to constrain a hydrological model in the context of a two-layer shallow aquifer with contrasted properties and thicknesses. MRS data provide information directly sensitive to water content with no need for any petrophysical relationships. Thus, the interpretation of the MRS signal is free of any perturbation related to observed lithological or mineralogical variations. Moreover, the information contained in an MRS survey provides a powerful tool to locally constrain the hydraulic parameters while covering the whole catchment. The methodology set up here requires neither calibration from core samples nor hydraulic tests, as the water content estimated by the hydrological model is directly inserted to estimate the MRS signal compared to the measured one.

The capacity of MRS to monitor the dynamics of water content fluctuations is also suggested at the rain event and at the seasonal scale. The synthetic tests performed underline that the locations of MRS stations should be strategically chosen beforehand because headwater catchments with steep slopes show highly varying water content dynamics with the location in the system. For instance, the MRS temporal variations might be null in some regions, for example, along the slopes or in the wetland. By contrast, flat areas located near upstream springs might be conducive to stronger hydrodynamic signals and subsequent significant MRS signal variations over time.

The acquisition of MRS data sets focusing on the first meters of the subsurface would allow for improving the methodology to delimit the variation ranges of the hydraulic parameter values and their probability density within a Bayesian framework. That being said, specific protocols of acquisition have first to be settled to properly address the issues associated with the low signal to noise ratio of MRS measurements when sounding the shallow subsurface. Then, the strategy employed in this study and post-conditioning a hydrological model via MRS data could be inserted in a coupled inversion scheme by fitting the MRS signals to determine the hydrological model parameters at the scale of the catchment. In this perspective, the hydrological model NIHM would probably be a suited tool because of its relative rapidity in simulating flow over the various compartments of a catchment. However, simulations are still too long for running the high number of models required by Monte Carlo approaches. An adapted design of the inversion scheme is thus required, and the use of the adjoint state in an inversion procedure of the "descent" type could become a first pioneering approach to the conditioning of an integrated hydrological model on the basis of MRS measurements together with stream flow rate data (Ackerer et al., 2014; Delay et al., 2017). 


\section{Acknowledgments}

The MRS acquisition campaign of this study was funded by CRITEX, INSU, and REALISE projects. The authors acknowledge Daniel Sultana (LTHE), Troels Thomsen (LTHE), Sylvain Benarioumlil (OHGE), and Valentin Gondy (OHGE) for their help in fieldwork. Meteorological and flow rate data collection was funded by the Observatoire Hydro-Géochimique de l'Environnement (OHGE), which is financially supported by CNRS/INSU France and the University of Strasbourg. OHGE is part of the OZCAR research infrastructure (http://www.ozcar-ri.org). The authors would like to acknowledge the OZCAR network for the scientific animation that has led to this study and the ANR HYDROCRIZSTO-15-CE01-0010-02 project. The French Ministry of Agriculture funded Benjamin Jeannot's Ph.D.

\section{CRediT author statement}

Nolwenn Lesparre: Conceptualization, Methodology, Software, Validation, Formal analysis, Writing Original Draft, Writing - Review \& Editing, Visualization Jean-François Girard: Conceptualization, Methodology, Software, Writing - Review \& Editing Benjamin Jeannot: Data Curation, Methodology, Software Sylvain Weill: Methodology, Writing - Review \& Editing Marc Dumont: Investigation, Data Curation, Writing - Review \& Editing Marie Boucher: Investigation, Resources, Data Curation, Project administration Daniel Viville: Investigation, Writing - Review \& Editing Marie-Claire Pierret: Investigation, Writing - Review \& Editing, Supervision, Project administration, Funding acquisition Anatoly Legchenko: Software, Investigation, Resources, Project administration, Funding acquisition Frederick Delay: Conceptualization, Methodology, Writing - Review \& Editing, Supervision

\section{References}

Ackerer, P., Trottier, N., Delay, F., 2014. Flow in double-porosity aquifers: Parameter estimation using an adaptive multiscale method. Adv. Water Resource., 73, 108-122. https://doi.org/10.1016/j.advwatres.2014.07.001

Ameli, A.A., Amvrosiadi, N., Grabs, T., Laudon, H., Creed, I.F., McDonnell, J.J., Bishop, K., 2016. Hillslope permeability architecture controls on subsurface transit time distribution and flow paths. J. Hydrol., 543, 17-30. https://doi.org/10.1016/j.jhydrol.2016.04.071

Angermann, L., Jackisch, C., Allroggen, N., Sprenger, M., Zehe, E., Tronicke, J., Weiler, M., Blume, T., 2017. Form and function in hillslope hydrology: Characterization of subsurface flow based on response observations. Hydrol. Earth Syst. Sc. 21, 3727-3748. https://doi.org/10.5194/hess-213727-201

Baltassat, J.M., Legchenko, A., Ambroise, B., Mathieu, F., Lachassagne, P., Wyns, R., Mercier, J.L., Schott, J.J., 2005. Magnetic resonance sounding (MRS) and resistivity characterisation of a mountain hard rock aquifer: The Ringelbach Catchment, Vosges Massif, France. Near Surf. Geophys., 3, 267-274. https://doi.org/10.3997/1873-0604.2005022

Banks, E.W., Simmons, C.T., Love, A.J., Cranswick, R., Werner, A.D., Bestland, E.A., Wood, M., Wilson, T., 2009. Fractured bedrock and saprolite hydrogeologic controls on groundwater/surfacewater interaction: a conceptual model (Australia). Hydrogeol. J., 17, 1969-1989. https://doi.org/10.1007/s10040-009-0490-7

Beaulieu, E., Lucas, Y., Viville, D., Chabaux, F., Ackerer, P., Goddéris, Y., Pierret, M.C., 2016. Hydrological and vegetation response to climate change in a forested mountainous catchment. Modeling Earth Systems and Environment, 2, 1-15. https://doi.org/10.1007/s40808-016-0244-1

Befus, K.M., Sheehan, A.F., Leopold, M., Anderson, S.P., Anderson, R.S., 2011. Seismic constraints on critical zone architecture, Boulder Creek Watershed, Front Range, Colorado. Vadose Zone J., 10(3), 915-927. https://doi.org/10.2136/vzj2010.0108 
Lesparre et al., 2020, J. of Hydrol.

Beven, K.J., Wood, E.F., Sivapalan, M., 1988. On hydrological heterogeneity-catchment morphology and catchment response. J. hydrol., 100, 353-375. https://doi.org/10.1016/00221694(88)90192-8

Binley, A., Hubbard, S.S., Huisman, J.A., Revil, A., Robinson, D.A., Singha, K., Slater, L.D., 2015. The emergence of hydrogeophysics for improved understanding of subsurface processes over multiple scales. Water Resour. Res., 51(6), 3837-3866. https://doi.org/10.1002/2015wr017016

Blumstock, M., Tetzlaff, D., Dick, J.J., Nuetzmann, G., Soulsby, C., 2016. Spatial organization of groundwater dynamics and streamflow response from different hydropedological units in a montane catchment. Hydrol. Process., 30(21), 3735-3753. https://doi.org/10.1002/hyp.10848

Boucher, M., Costabel, S., Yaramanci, U., 2011. The detectability of water by NMR considering the instrumental dead time: A laboratory analysis of unconsolidated materials. Near Surf. Geophys., 9, 145-153. https://doi.org/10.3997/1873-0604.2010056

Boucher, M., Favreau, G., Nazoumou, Y., Cappelaere, B., Massuel, S., Legchenko, A., 2012. Constraining groundwater modeling with magnetic resonance soundings. Groundwater, 50(5), 775784. https://doi.org/10.1111/j.1745-6584.2011.00891.x.

Boucher, M., Pierret, M.C., Dumont, M., Viville, D., Legchenko, A., Chevalier, A., Penz S., 2015. MRS characterisation of a mountain hard rock aquifer: The Strengbach catchment, Vosges Massif, France. Paper presented at: 6th International Workshop on the Magnetic Resonance Sounding, Aarhus, Denmark. 8-10 June 2015. Abstract G07.MRS2015.

Cassiani, G., Godio, A., Stocco, S., Villa, A., Deiana, R., Frattini, P., Rossi, M., 2009. Monitoring the hydrologic behaviour of a mountain slope via time-lapse electrical resistivity tomography. Near Surf. Geophys., 7(5-6), 475-486. https://doi.org/ 10.3997/1873-0604.2009013

Cassidy, R., Comte, J.C., Nitsche, J., Wilson, C., Flynn, R., Ofterdinger, U., 2014. Combining multi-scale geophysical techniques for robust hydro-structural characterisation in catchments underlain by hard rock in post-glacial regions. J. Hydrol., 517, 715-731. https://doi.org/10.1016/j.jhydrol.2014.06.004

Chen, J., Hubbard, S., Rubin, Y., 2001. Estimating the hydraulic conductivity at the South Oyster Site from geophysical tomographic data using Bayesian techniques based on the normal linear regression model. Water Resour. Res., 37, 1603-1613. https://doi.org/10.1029/2000WR900392

Chorover, J., Derry, L.A., McDowell, W.H., 2017. Concentration-Discharge Relations in the Critical Zone: Implications for Resolving Critical Zone Structure, Function, and Evolution. Water Resour. Res., 53(11), 8654-8659. https://doi.org/10.1002/2017WR021111

Christensen, N.K., Christensen, S., Ferre, T.P.A., 2016. Testing alternative uses of electromagnetic data to reduce the prediction error of groundwater models. Hydrol. Earth Syst. Sc., 20(5), 1925-1946. https://doi.org/10.5194/hess-20-1925-2016

Comte, J.C., Ofterdinger, U., Legchenko, A., Caulfield, J., Cassidy, R., González, J.M., 2019. Catchment-scale heterogeneity of flow and storage properties in a weathered/fractured hard rock aquifer from resistivity and magnetic resonance surveys: implications for groundwater flow paths and the distribution of residence times. Geol. Soc. Spec. Pub., 479(1), 35-58. https://doi.org/10.1144/SP479.11

Costabel, S., Günther, T., 2014. Noninvasive estimation of water retention parameters by observing the capillary fringe with magnetic resonance sounding. Vadose Zone J., 13(6). https://doi.org/10.2136/vzj2013.09.0163

Daily, W., Ramirez, A., LaBrecque, D., Nitao, J., 1992. Electrical resistivity tomography of vadose water movement, Water Resour. Res., 28(5), 1429-1442. https://doi.org/10.1029/91WR03087 
Dalgaard, E., Auken, E., Larsen, J.J., 2012. Adaptive noise cancelling of multichannel magnetic resonance sounding signals. Geophys. J. Int., 191(1), 88-100. https://doi.org/10.1111/j.1365246X.2012.05618.x

Delay, F., Badri, H., Fahs, M., Ackerer, P., 2017. A comparison of discrete versus continuous adjoint states to invert groundwater flow in heterogeneous dual porosity systems. Adv. Water Resour., 110, 1-18. https://doi.org/10.1016/j.advwatres.2017.09.022

Descloitres, M., Ruiz, L., Sekhar, M., Legchenko, A., Braun, J.J., Mohan Kumar, M.S., Subramanian, S., 2008. Characterization of seasonal local recharge using electrical resistivity tomography and magnetic resonance sounding. Hydrol. Process., 22(3), 384-394. https://doi.org/10.1002/hyp.6608

Diek, S., Temme, A.J., Teuling, A.J., 2014. The effect of spatial soil variation on the hydrology of a semi-arid Rocky Mountains catchment. Geoderma, 235, 113-126. https://doi.org/10.1016/j.geoderma.2014.06.028

Dlugosch, R., Günther T., Müller-Petke M., Yaramanci U., 2013. Improved prediction of hydraulic conductivity for coarse-grained, unconsolidated material from nuclear magnetic resonance. Geophysics, 78, EN55-EN64. https://doi.org/10.1190/geo2012-0187.1

Dwivedi, R., Meixner, T., McIntosh, J.C., Ferré, P.T., Eastoe, C.J., Niu, G.Y., Minor, R.L., BarronGafford, G.A., Chorover, J., 2019. Hydrologic functioning of the deep critical zone and contributions to streamflow in a high-elevation catchment: Testing of multiple conceptual models. Hydrol. Process., 33(4), 476-494. https://doi.org/10.1002/hyp.13363

Ebel, B.A., Loague, K., 2006. Physics-based hydrologic-response simulation: Seeing through the fog of equifinality. Hydrol. Process., 20(13), 2887-2900. https://doi.org/10.1002/Zhyp.6388

El Gh'Mari, A., 1995. Etude minéralogique, pétrophysique et géochimique de la dynamique d'altération d'un granite soumis aux dépôts atmosphériques acides (bassin versant du Strengbach, Vosges, France): Mécanismes, bilans et modélisations. Ph.D. diss. Strasbourg 1 Univ., Strasbourg, France.

Falzone S., Keating K., 2016. A laboratory study to determine the effect of pore size, surface relaxivity, and saturation on NMR T2 relaxation measurements. Near Surf. Geophys., 14, 57-69, doi:10.3997/1873-0604.2016001.

Fichter, J., Dambrine, E., Turpault, M.P., Ranger., J., 1998a. Base cation supply in spruce and beech ecosystems of the Strengbach catchment (Vosges mountains, NE France). Water Air Soil Poll. 04:125-148. doi:10.1023/A:1004966302517

Fichter, J., Turpault, M.P., Dambrine, E., Ranger J., 1998b. Mineral evolution of acid forest soils in the Strengbach catchment (Vosges mountains, NE France). Geoderma, 82:315-340. doi:10.1016/S0016-7061(97)00107-9

Flinchum, B.A., Holbrook, W.S., Rempe, D., Moon, S., Riebe, C.S., Carr, B.J., Hayes, J.L., St. Clair, J., Peters, M.P., 2018a. Critical zone structure under a granite ridge inferred from drilling and threedimensional seismic refraction data. J. Geophys. Res. Eart, 123(6), 1317-1343. https://doi.org/10.1002/hyp.13260

Flinchum, B.A., Holbrook, W.S., Grana, D., Parsekian, A.D., Carr, B.J., Hayes, J.L., Jiao, J., 2018b. Estimating the water holding capacity of the critical zone using near-surface geophysics. Hydrol. Process., 32(22), 3308-3326. https://doi.org/

Francés, A.P., Lubczynski, M.W., Roy, J., Santos, F.A., Ardekani, M.R.M., 2014. Hydrogeophysics and remote sensing for the design of hydrogeological conceptual models in hard rocks-Sardón catchment (Spain). J. Appl. Geophys., 110, 63-81. https://doi.org/10.1016/j.jappgeo.2014.08.015 
Lesparre et al., 2020, J. of Hydrol.

Gabrielli, C.P., McDonnell, J.J., Jarvis, W.T., 2012. The role of bedrock groundwater in rainfallrunoff response at hillslope and catchment scales. J. Hydrol., 450, 117-133. https://doi.org/10.1016/j.jhydrol.2012.05.023

Gannon, J.P., Bailey, S.W., McGuire, K.J., 2014. Organizing groundwater regimes and response thresholds by soils: A framework for understanding runoff generation in a headwater catchment. Water Resour. Res., 50(11), 8403-8419. https://doi.org/10.1002/2014WR015498

Gottschalk, I.P., Hermans, T., Knight, R., Caers, J., Cameron, D.A., Regnery, J., McCray, J.E., 2017. Integrating non-colocated well and geophysical data to capture subsurface heterogeneity at an aquifer recharge and recovery site. J. Hydrol., 555, 407-419. https://doi.org/10.1016/j.jhydrol.2017.10.028

Grunewald, E., Knight, R., Walsh, D., 2014. Advancement and validation of surface nuclear magnetic resonance spin-echo measurements of T2 Surface NMR spin-echo T2. Geophysics, 79, EN15EN23. https://doi.org/10.1190/geo2013-0105.1

Günther, T., Müller-Petke, M., 2012. Hydraulic properties at the North Sea island of Borkum derived from joint inversion of magnetic resonance and electrical resistivity soundings. Hydrol. Earth Syst. Sc., 16(9), 3279-3291. https://doi.org/10.5194/hess-16-3279-2012

Herckenrath, D., Auken, E., Christiansen, L., Behroozmand, A.A., Bauer-Gottwein, P., 2012. Coupled hydrogeophysical inversion using time-lapse magnetic resonance sounding and time-lapse gravity data for hydraulic aquifer testing: Will it work in practice? Water Resour. Res., 48(1). https://doi.org/10.1029/2011WR010411

Hinnell, A.C., Ferré, T.P.A., Vrugt, J.A., Huisman, J.A., Moysey, S., Rings, J., Kowalsky, M.B., 2010. Improved extraction of hydrologic information from geophysical data through coupled hydrogeophysical inversion. Water Resour. Res., 46. https://doi.org/10.1029/2008WR007060

Holbrook, W.S., Riebe, C.S., Elwaseif, M., Hayes, J.L., Basler-Reeder, K., Harry, D.L., Mlzian, A., Dosseto, A., Hartsough, P.C., Hopmans, J.W., 2014. Geophysical constraints on deep weathering and water storage potential in the Southern Sierra Critical Zone Observatory. Earth Surf. Proc. Land., 39(3), 366-380. https://doi.org/10.1002/esp.3502

Holbrook, W.S., Marcon, V., Bacon, A.R., Brantley, S.L., Carr, B.J., Flinchum, B.A., Richter, D.D., Riebe, C.S., 2019. Links between physical and chemical weathering inferred from a 65-m-deep borehole through Earth's critical zone. Sci. Rep., 9(1), 4495. https://doi.org/10.1038/s41598-01940819-9.

Hübner, R., Günther, T., Heller, K., Noell, U., Kleber, A., 2017. Impacts of a capillary barrier on infiltration and subsurface stormflow in layered slope deposits monitored with 3-D ERT and hydrometric measurements. Hydrol. Earth Syst. Sci., 21, 5181. https://doi.org/10.5194/hess-21-51812017

Jackisch, C., Angermann, L., Allroggen, N., Sprenger, M., Blume, T., Tronicke, J., Zehe, E., 2017. Form and function in hillslope hydrology: in situ imaging and characterization of flow-relevant structures. Hydrol. Earth Syst. Sci., 21, 3749-3775. https://doi.org/10.5194/hess-21-3749-2017.

Jeannot, B., Weill, S., Eschbach, D., Schmitt, L., Delay, F., 2018. A low-dimensional integrated subsurface hydrological model coupled with 2-D overland flow: Application to a restored fluvial hydrosystem (Upper Rhine River-France). J. Hydrol., 563, 495-509. https://doi.org/10.1016/j.jhydrol.2018.06.028

Jeannot, B., Weill, S., Eschbach, D., Schmitt, L., Delay, F., 2019. Assessing the effect of flood restoration on surface-subsurface interactions in Rohrschollen Island (Upper Rhine river-France) using integrated hydrological modeling and thermal infrared imaging. Hydrol. Earth Syst. Sc., 23(1), 239-254. https://doi.org/10.5194/hess-23-239-2019 
Lesparre et al., 2020, J. of Hydrol.

Kenyon, W.E., 1997. Petrophysical principles of applications of NMR logging. The Log Analyst, 38(02).

Kim, H., Dietrich, W.E., Thurnhoffer, B.M., Bishop, J.K., Fung, I.Y., 2017. Controls on solute concentration-discharge relationships revealed by simultaneous hydrochemistry observations of hillslope runoff and stream flow: The importance of critical zone structure. Water Resour. Res., 53(2), 1424-1443. https://doi.org/10.1002/2016WR019722

Kleinberg, R.L., Kenyon, W.E., Mitra, P.P., 1994. Mechanism of NMR relaxation of fluids in rock. J. Magnetic Reson., 108, 206-206. https://doi.org/10.1006/jmra.1994.1112

Koch, K., Wenninger, J., Uhlenbrook, S., Bonell, M., 2009. Joint interpretation of hydrological and geophysical data: electrical resistivity tomography results from a process hydrological research site in the Black Forest Mountains, Germany. Hydrol. Process., 23(10), 1501-1513. https://doi.org/10.1002/hyp.7275

Koch, J.C., Toohey, R.C., Reeves, D.M., 2017. Tracer-based evidence of heterogeneity in subsurface flow and storage within a boreal hillslope. Hydrol. Process., 31(13), 2453-2463. https://doi.org/10.1002/hyp.11205

Koïta, M., Yonli, H., Soro, D., Dara, A., Vouillamoz, J.M., 2017. Taking into Account the Role of the Weathering Profile in Determining Hydrodynamic Properties of Hard Rock Aquifers. Geosciences, 7(3), 89. https://doi.org/10.3390/geosciences7030089

Koïta, M., Yonli, H., Soro, D., Dara, A., Vouillamoz, J.M., 2018. Groundwater Storage Change Estimation Using Combination of Hydrogeophysical and Groundwater Table Fluctuation Methods in Hard Rock Aquifers. Resources, 7, 5. https://doi.org/10.3390/resources7010005

Kosugi, K.I., Fujimoto, M., Katsura, S.Y., Kato, H., Sando, Y., Mizuyama, T., 2011. Localized bedrock aquifer distribution explains discharge from a headwater catchment. Water Resour. Res., 47(7). https://doi.org/10.1029/2010WR009884

Kotikian, M., Parsekian, A.D., Paige, G., Carey, A., 2019. Observing Heterogeneous Unsaturated Flow at the Hillslope Scale Using Time-Lapse Electrical Resistivity Tomography. Vadose Zone J., 18(1). https://doi.org/10.2136/vzj2018.07.0138

Legchenko, A., Valla, P., 2002. A review of the basic principles for proton magnetic resonance sounding measurements. J. Appl. Geophys., 50(1-2), 3-19. https://doi.org/10.1016/S09269851(02)00127-1

Legchenko, A., Baltassat, J.M., Bobachev, A., Martin, C., Robain, H., Vouillamoz, J.M., 2004. Magnetic resonance sounding applied to aquifer characterization. Groundwater, 42(3), 363-373. https://doi.org/10.1111/j.1745-6584.2004.tb02684.x

Legchenko, A., Descloitres, M., Bost, A., Ruiz, L., Reddy, M., Girard, J.F., Sekhar, M., Kumar, M.S.M., Braun, J.J., 2006. Resolution of MRS applied to the characterization of hard-rock aquifers. Groundwater, 44(4), 547-554. https://doi.org/10.1111/j.1745-6584.2006.00198.x

Legchenko, A., Vouillamoz, J. M., Roy, J., 2010. Application of the magnetic resonance sounding method to the investigation of aquifers in the presence of magnetic materials. Geophysics, 75, L91L100. https://doi.org/10.1190/1.3494596

Léger, E., Saintenoy, A., Coquet, Y., 2014. Hydrodynamic parameters of a sandy soil determined by ground-penetrating radar inside a single ring infiltrometer. Water Resour. Res., 50(7), 5459-5474. https://doi.org/10.1002/2013WR014226

Lesparre, N., Girard, J.F., Jeannot, B., Weill, S., Dumont, M., Boucher, M., Viville, D., Pierret, M.C., Legchenko, A., Delay, F. Magnetic resonance sounding dataset of a hard-rock headwater 
Lesparre et al., 2020, J. of Hydrol.

catchment for assessing the vertical distribution of water contents in the subsurface, submitted to Data in Brief.

Maxwell, R.M., Putti, M., Meyerhoff, S., Delfs, J.O., Ferguson, I.M., Ivanov, V., Kim, J., Kolditz, O., Kollet, S.J., Kumar, M., Lopez, S., Niu, J., Paniconi, C., Park, Y.J., Phanikumar, M.S., Shen, C., Sudicky, E.A., Sulis, M., 2014. Surface-subsurface model intercomparison: A first set of benchmark results to diagnose integrated hydrology and feedbacks. Water Resour. Res., 50, 1531-1549. https://doi.org/10.1002/2013WR013725

Mazzilli, N., Boucher, M., Chalikakis, K., Legchenko, A., Jourde, H., Champollion, C., 2016. Contribution of magnetic resonance soundings for characterizing water storage in the unsaturated zone of karst aquifers. Geophysics, 81, WB49-WB61. https://doi.org/10.1190/geo2015-0411.1

McMillan, H.K., Srinivasan, M.S., 2015. Characteristics and controls of variability in soil moisture and groundwater in a headwater catchment. Hydrol. Earth Syst. Sc., 19, 1767-1786. https://doi.org/10.5194/hess-19-1767-2015

Merz, S., Balcom, B.J., Enjilela, R., Vanderborght, J., Rothfuss, Y., Vereecken, H., Pohlmeier, A., 2018. Magnetic resonance monitoring and numerical modeling of soil moisture during evaporation. Vadose Zone J., 17. doi:10.2136/vzj2016.10.0099

Mohnke, O., Yaramanci, U., 2008. Pore size distributions and hydraulic conductivities of rocks derived from magnetic resonance sounding relaxation data using multi-exponential decay time inversion. J. Appl. Geophys., 66, 73-81. https://doi.org/10.1016/j.jappgeo.2008.05.002

Mota, R., Monteiro Santos, F.A., 2010. 2D sections of porosity and water saturation from integrated resistivity and seismic surveys. Near Surf. Geophys., 8, 575-584. https://doi.org/10.3997/1873-0604.2010042.

Mualem, Y., 1976. A new model for predicting the hydraulic conductivity of unsaturated porous media. Water Resour. Res. 12, 513-522. https://doi.org/10.1029/WR012i003p00513

Olyphant, J., Pelletier, J.D., Johnson, R., 2016. Topographic correlations with soil and regolith thickness from shallow-seismic refraction constraints across upland hillslopes in the Valles Caldera, New Mexico. Earth Surf. Proc. Land., 41(12), 1684-1696. https://doi.org/10.1002/esp.3941

Orlando, J., Comas, X., Hynek, S.A., Buss, H.L., Brantley, S.L., 2016. Architecture of the deep critical zone in the Rio Icacos watershed (Luquillo Critical Zone Observatory, Puerto Rico) inferred from drilling and ground penetrating radar (GPR). Earth Surf. Proc. Land., 41(13), 1826-1840. https://doi.org/10.1002/esp.3948

Pan, Y., Weill, S., Ackerer, P., Delay, F., 2015. A coupled stream flow and depth-integrated subsurface flow model for catchment hydrology. J. Hydrol., 530, 66-78. https://doi.org/10.1016/j.jhydrol.2015.09.044

Parsekian, A.D., Singha, K., Minsley, B.J., Holbrook, W.S., Slater, L., 2015. Multiscale geophysical imaging of the critical zone. Rev. Geophys., 53(1), 1-26. https://doi.org/10.1002/2014RG000465

Penman, H. L., 1948. Natural evaporation from open water, bare soil and grass. P. Roy. S. Lond. Series A. Mat., 193(1032), 120-145. https://doi.org/10.1098/rspa.1948.0037

Pierret, M.C., Cotel, S., Ackerer, P., Beaulieu, E., Benarioumlil, S., Boucher, M., Boutin, R., Chabaux, F., Delay, F., Fourtet, C., Friedmann, P., Fritz, B., Gangloff, S., Girard, J.-F., Legtchenko, A., Viville, D., Weill, S., Probst, A., 2018. The Strengbach catchment: A multidisciplinary environmental sentry for 30 years. Vadose Zone J., 17(1). https://doi.org/10.2136/vzj2018.04.0090

Pierret, M.C., Viville, D., Dambrine, E., Cotel, S., Probst, A., 2019. Twenty-five-year record of chemicals in open field precipitation and throughfall from a medium-altitude forest catchment 
Lesparre et al., 2020, J. of Hydrol.

(Strengbach-NE France): An obvious response to atmospheric pollution trends. Atmos. Environ., 202, 296-314. https://doi.org/10.1016/j.atmosenv.2018.12.026

Rehman, F., Abouelnaga, H.S.O., Rehman, F., 2016. Estimation of dielectric permittivity, water content, and porosity for environmental engineering and hydrogeological studies using ground penetrating radar, a short review. Arab. J. Geosci., 9(4), 312. https://doi.org/10.1007/s12517-0162328-7

Rempe, D.M., Dietrich, W.E., 2014. A bottom-up control on fresh-bedrock topography under landscapes. P. Natl. Acad. Sci. USA., 111(18), 6576-6581. https://doi.org/10.1002/esp.4052

Riebe, C.S., Hahm, W.J., Brantley, S.L., 2017. Controls on deep critical zone architecture: A historical review and four testable hypotheses. Earth Surf. Proc. Land., 42(1), 128-156. https://doi.org/

Rinderer, M., Van Meerveld, H.J., Seibert, J., 2014. Topographic controls on shallow groundwater levels in a steep, prealpine catchment: When are the TWI assumptions valid?. Water Resour. Res., 50(7), 6067-6080. https://doi.org/10.1002/2013WR015009.

Sailhac, P., Bano, M., Behaegel, M., Girard, J.F., Para, E.F., Ledo, J., Marquis, G., Matthey, P.D., Ortega-Ramírez, J., 2009. Characterizing the vadose zone and a perched aquifer near the Vosges ridge at the La Soutte experimental site, Obernai, France. C. R. Geosci., 341(10-11), 818-830. https://doi.org/10.1016/j.crte.2009.07.015

Salve, R., Rempe, D.M., Dietrich, W.E., 2012. Rain, rock moisture dynamics, and the rapid response of perched groundwater in weathered, fractured argillite underlying a steep hillslope. Water Resour. Res., 48. https://doi.org/10.1029/2012WR012583

Shushakov, O.A., Fomenko, V.M., 2004. Surface-NMR relaxation and echo of aquifers in geomagnetic field. Appl. Magn. Reson., 25, 599. https://doi.org/10.1007/BF03166551

Scaini, A., Hissler, C., Fenicia, F., Juilleret, J., Iffly, J.F., Pfister, L., Beven, K., 2018. Hillslope response to sprinkling and natural rainfall using velocity and celerity estimates in a slate-bedrock catchment. J. Hydrol., 558, 366-379. https://doi.org/10.1016/j.jhydrol.2017.12.011

Singh, N.K., Emanuel, R.E., Nippgen, F., McGlynn, B.L., Miniat, C.F., 2018. The relative influence of storm and landscape characteristics on shallow groundwater responses in forested headwater catchments. Water Resour. Res., 54(12), 9883-9900. https://doi.org/10.1029/2018WR022681

Slater, L., 2007. Near surface electrical characterization of hydraulic conductivity: From petrophysical properties to aquifer geometries-A review. Surv. Geophys., 28(2-3), 169-197. https://doi.org/10.1007/s10712-007-9022-y.

Soulsby, C., Bradford, J., Dick, J., McNamara, J.P., Geris, J., Lessels, J., Blumstock, M., Tetzlaff, D., 2016. Using geophysical surveys to test tracer-based storage estimates in headwater catchments. Hydrol. Process., 30(23), 4434-4445. https://doi.org/10.1002/hyp.10889

Turesson, A., 2006. Water content and porosity estimated from ground-penetrating radar and resistivity. J. Appl. Geophys., 58, 99-111. https://doi.org/10.1016/j.jappgeo.2005.04.004.

Van Genuchten, M.T., 1980. A closed-form equation for predicting the hydraulic conductivity of unsaturated soils. Soil Sci. Soc. Am. J., 44(5), 892-898. https://doi.org/10.2136/sssaj1980.03615995004400050002x

Vilhelmsen, T.N., Behroozmand, A.A., Christensen, S., Nielsen, T.H., 2014. Joint inversion of aquifer test, MRS, and TEM data. Water Resources Research, 50, 3956-3975. https://doi.org/10.1002/2013WR014679

Viville, D., Biron, P., Granier, A., Dambrine, E., Probst, A., 1993. Interception in a mountainous declining spruce stand in the Strengbach catchment (Vosges, France). J. Hydrol., 144(1-4), 273-282. https://doi.org/10.1016/0022-1694(93)90175-9 
Lesparre et al., 2020, J. of Hydrol.

Vouillamoz, J.M., Sokheng, S., Bruyere, O., Caron, D., Arnout, L., 2012. Towards a better estimate of storage properties of aquifer with magnetic resonance sounding. J. Hydrol., 458-459, 5158, http://dx.doi.org/10.1016/j.jhydrol.2012.06.044.

Vouillamoz, J.M., Lawson, F.M.A., Yalo, N., Descloitres, M., 2014. The use of magnetic resonance sounding for quantifying specific yield and transmissivity in hard rock aquifers: The example of Benin. J. Appl. Geophys., 107, 16-24. https://doi.org/10.1016/j.jappgeo.2014.05.012

Vouillamoz, J.M., Lawson, F.M.A., Yalo, N., Descloitres, M., 2015. Groundwater in hard rocks of Benin: Regional storage and buffer capacity in the face of change. J. Hydrol., 520, 379-386. https://doi.org/10.1016/j.jhydrol.2014.11.024

Weill, S., Delay, F., Pan, Y., Ackerer, P., 2017. A low-dimensional subsurface model for saturated and unsaturated flow processes: ability to address heterogeneity. Computat. Geosci., 21(2), 301-314. https://doi.org/10.1007/s10596-017-9613-8

Weill, S., Lesparre N., Jeannot B., Delay, F., 2019. Variability of water transit time distributions at the Strengbach catchment (Vosges Mountains, France) inferred through integrated hydrological modeling and particle tracking algorithms. Water, 11(12), 2637. https://doi.org/10.3390/w11122637

Welch, L.A., Allen, D.M., 2014. Hydraulic conductivity characteristics in mountains and implications for conceptualizing bedrock groundwater flow. Hydrogeol. J., 22(5), 1003-1026. https://doi.org/10.1007/s10040-014-1121-5

Winter, T.C., 2007. The Role of Ground Water in Generating Streamflow in Headwater Areas and in Maintaining Base Flow. J. Am. Water Resour. As., 43, 15-25. https://doi.org/10.1111/j.17521688.2007.00003.x

Wymore, A.S., Brereton, R.L., Ibarra, D.E., Maher, K., McDowell, W.H., 2017. Critical zone structure controls concentration-discharge relationships and solute generation in forested tropical montane watersheds. Water Resour. Res., 53, 6279-6295. https://doi.org/10.1002/2016WR020016

Wyns, R., Baltassat, J.M., Lachassagne, P., Legchenko, A., Vairon, J., Mathieu, F., 2004. Application of proton magnetic resonance soundings to groundwater reserve mapping in weathered basement rocks (Brittany, France). B. Soc. Géol. Fr., 175, 21-34. https://doi.org/10.2113/175.1.21 